This item was submitted to Loughborough's Research Repository by the author.

Items in Figshare are protected by copyright, with all rights reserved, unless otherwise indicated.

\title{
Morphology and evolution of bars in a wandering gravel-bed river; lower Fraser River, British Columbia, Canada
}

PLEASE CITE THE PUBLISHED VERSION

\section{PUBLISHER}

Blackwell / @ International Association of Sedimentologists

VERSION

AM (Accepted Manuscript)

\section{LICENCE}

CC BY-NC-ND 4.0

\section{REPOSITORY RECORD}

Rice, Stephen P., Michael Church, Colin L. Wooldridge, and Edward Hickin. 2019. "Morphology and Evolution of Bars in a Wandering Gravel-bed River; Lower Fraser River, British Columbia, Canada". figshare. https://hdl.handle.net/2134/4424. 
This item was submitted to Loughborough's Institutional Repository (https://dspace.lboro.ac.uk/) by the author and is made available under the following Creative Commons Licence conditions.

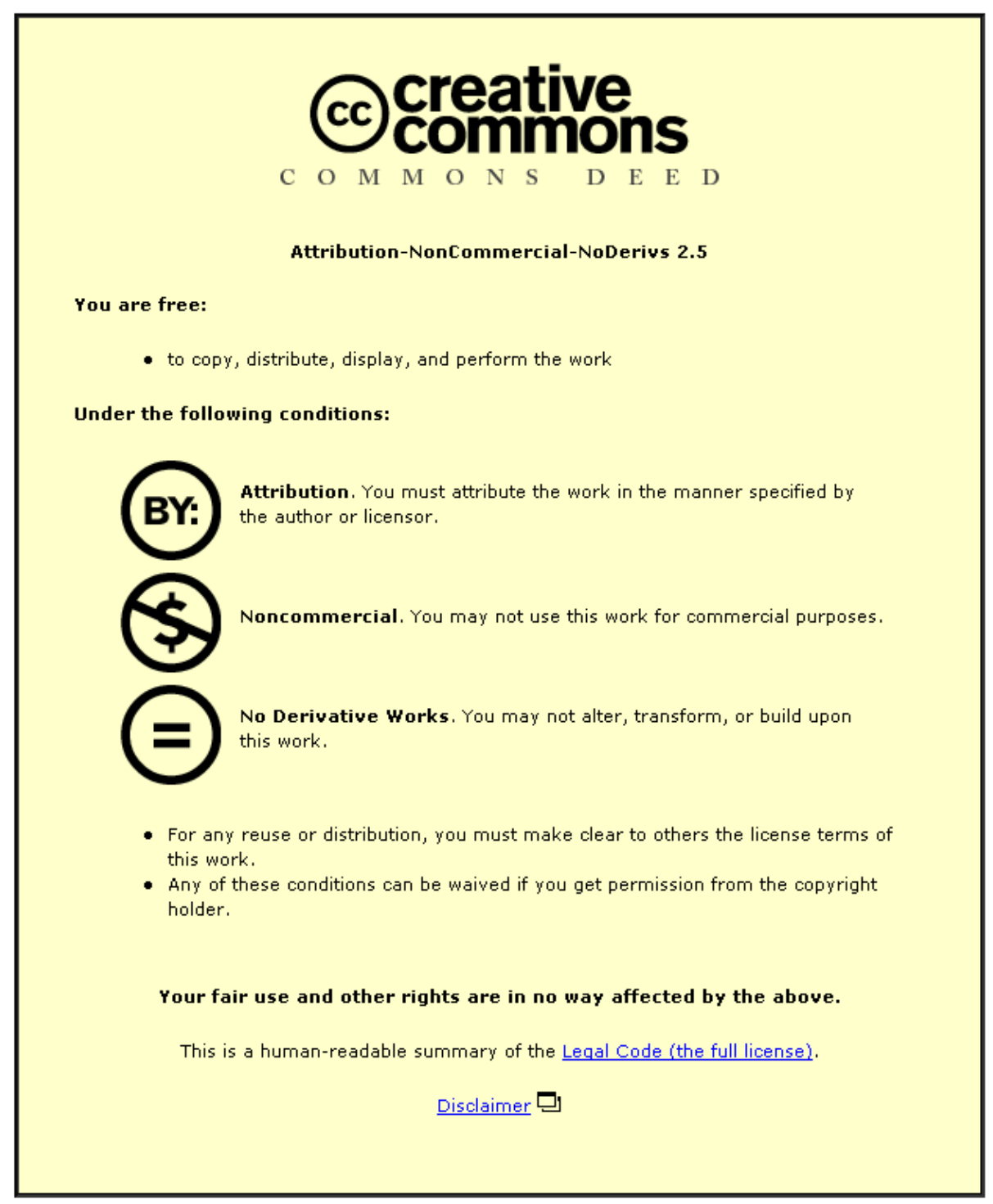

For the full text of this licence, please go to: http://creativecommons.org/licenses/by-nc-nd/2.5/ 


\title{
Morphology and evolution of bars in a wandering gravel-bed river; lower Fraser River, British Columbia, Canada
}

\author{
STEPHEN P. RICE ${ }^{1}$, MICHAEL CHURCH ${ }^{2}$, COLIN L. WOOLDRIDGE ${ }^{*}$, EDWARD J. \\ HICKIN $^{3}$ \\ This is an author-produced version of the refereed and revised paper published in \\ Sedimentology 56(3), April 2009, p 709-736 \\ DOI: $10.1111 / \mathrm{j} .1365-3091.2008 .00994 . x$ \\ http://www3.interscience.wiley.com/journal/118503415/home
}

\begin{abstract}
A hierarchical typology for the channels and bars within aggradational wandering gravel-bed rivers is developed from an examination of a $50 \mathrm{~km}$ reach of lower Fraser River, British Columbia, Canada. Unit bars, built by stacking of gravelly bedload sheets, are the key dynamic element of the sediment transfer system, linking sediment transport during individual freshets to the creation, development and remoulding of compound bar platforms that have either a lateral or medial style. Primary and secondary unit bars are identified, respectively, as those that deliver sediment to compound bars from the principal channel and those that redistribute sediment across the compound bar via seasonal anabranches and smaller channels. The record of bar accretion evident in ground penetrating radar sequences is consistent with the long-term development of bar complexes derived from historical aerial photographs. For two compound bars, inter-annual changes associated with individual sediment transport episodes are measured using detailed topographic surveys and longer-term changes are quantified using sediment budgets derived for individual bars from periodic channel surveys. Annual sediment turnover on the bars is comparable with the bed material transfer rate along the channel, indicating that relatively little bed material bypasses the bars. Bar construction and change are mainly accomplished by lateral accretion since the river has limited capacity to raise bed load onto higher surfaces. Styles of accretion and erosion and therefore the major bar-form morphologies on Fraser River are familiar and consistent with those in gravelly braided channels, but the wandering style does exhibit some distinctive features. For example, 65-year histories reveal the potential for long sequences of uninterrupted accretion in relatively stable wandering rivers that are unlikely in braided rivers.
\end{abstract}

Keywords: unit bars, compound bars, alluvial stratigraphy, sediment accretion, radar, river history

\section{INTRODUCTION}

At the scale of the channel, bars are the dominant feature of alluvial river morphology. They are a key expression of river behaviour, providing information about active processes and the sediment regime at the reach scale. In addition, they are repositories of sedimentary

\footnotetext{
1. Department of Geography, Loughborough University, Loughborough, Leicestershire, LE11 3TU, UK. (s.rice@lboro.ac.uk)

2. Department of Geography, The University of British Columbia, Vancouver, BC, Canada.

3. Department of Geography, Simon Fraser University, Vancouver, BC, Canada

* Deceased
} 
information that can be interpreted as the alluvial signature of palaeoenvironments. The form and development of bars in gravel-bed rivers has been the focus of a significant body of work, most of it necessarily qualitative and based on synoptic observations. Bridge (2003) and others have suggested that the development and validation of models that relate alluvial stratigraphy to particular depositional styles, from which palaeoenvironmental inferences can be made, requires additional primary data from modern rivers. They argue that there is a paucity of quantitative information about processes and patterns of sediment erosion and deposition at the bar scale and about the sedimentary structures produced by both short- and long-term geomorphological processes.

Recent advances in photogrammetric and surveying technologies (e.g. Lane, 2001) mean that quantifying short- and long-term geomorphological change is now relatively straightforward where an archive of photographic and (or) bathymetric data exists. Moreover, the subsurface architecture of modern gravel-bed rivers has recently been made accessible by groundpenetrating radar (Leclerc and Hickin, 1997; Roberts et al., 1997; Lunt et al., 2004; Wooldridge and Hickin, 2005) making it possible to relate contemporary patterns of sediment transport and bar modification directly to the architecture of preserved units.

In this paper these developments are brought together to examine the geomorphology of compound gravel bars in a large, wandering river, lower Fraser River in British Columbia, Canada. Several studies have examined the depositional processes and sedimentary products of wandering channels (Church, 1983; Ferguson and Werrity, 1983; Desloges and Church, 1987; Brierley, 1989; Brierley, 1991; Passmore and Macklin, 2000; Fuller et al., 2003; Burge, 2005, 2006; Burge and Lapointe, 2005), although none as large as Fraser River. We extend this work by providing (1) a hierarchical typology for the wandering style that includes compound barforms and supra-platform features, (2) a detailed account of the evolution of two bars that reveals the fundamental importance of unit bars (Smith, 1974) as the link between annual transport episodes and long-term change, (3) quantitative estimates of annual and long-term accretion and erosion rates for unit and compound-bars and (4) description of the three-dimensional stratigraphy of bar deposits in relation to bar development. We demonstrate the links between short-term processes and longer-term evolution, and make quantitative estimates of rates of bar-scale morphological change. This work is informed by detailed topographic surveys that bracket annual flood events, by GPR surveys and by a quantitative understanding of decennial-scale bar change derived from historical maps and aerial photographs.

\section{LOWER FRASER RIVER}

Fraser River drains $250000 \mathrm{~km}^{2}$ of British Columbia, Canada. Valleys in the upper basin are filled with Pleistocene deposits from which much of the sediment load is supplied. Approximately $350 \mathrm{~km}$ upstream from its delta, the river enters Fraser Canyon, emerging 170 $\mathrm{km}$ from the sea into the lower Fraser valley. Here the river escapes confinement, encounters a much lower gradient and deposits its gravel load. The gravel reach extends about $50 \mathrm{~km}$ from Laidlaw to Sumas Mountain, immediately upstream from the town of Mission (Figure 1), where there is a rapid transition to a single-thread, sand-bed channel. Through the gravel reach the active channel zone is between one and two kilometres wide, though now partially constrained by flood defences. At Agassiz (Figure 1), the river flows in a single channel that is $512 \mathrm{~m}$ wide at mean annual flood stage, has a mean depth of $6.6 \mathrm{~m}$, a mean velocity of 2.6 $\mathrm{m} \mathrm{s}^{-1}$ and a gradient of $4.8 \times 10^{-4}$, while at Mission (sand bed) the corresponding figures are $\mathrm{w}$ $=540 \mathrm{~m}, \mathrm{~d}=12.6 \mathrm{~m}, \mathrm{v}=1.5 \mathrm{~m} \mathrm{~s}^{-1}$ and $\mathrm{S}=5.0 \times 10^{-5}$ (McLean and Church, 1999). 
The annual hydrograph is dominated by snowmelt so that most sediment transport, deposition and reworking occur during the annual freshet in late spring and early summer. Mean annual flow at Mission is $3410 \mathrm{~m}^{3} \mathrm{~s}^{-1}$, the mean annual flood is $9790 \mathrm{~m}^{3} \mathrm{~s}^{-1}$ and the largest measured flood (1972) reached approximately $14400 \mathrm{~m}^{3} \mathrm{~s}^{-1}$ (the 1948 flood of record on the river would have reached between 16200 and $16500 \mathrm{~m}^{3} \mathrm{~s}^{-1}$ at Mission). Median grain-size on bar surfaces declines from approximately 53 to $17 \mathrm{~mm}$ along the gravel reach; corresponding values for the bulk sediment are 25 to $10 \mathrm{~mm}$. There is a clear downstream fining trend but local variability is consistently high and within individual bars, grain-size variations are structured according to longitudinal position, elevation and morphological setting.

The wandering style (Church, 1983) represents a transitional morphology between braiding and meandering (Ferguson and Werrity, 1983) with irregular sinuosity that is generally lower than in freely meandering rivers but where channel division is less continuous and less intense than in braided rivers. A principal channel about $500 \mathrm{~m}$ wide can be identified along most of the lower Fraser gravel reach but the flow is frequently split by vegetated islands into two or three perennial or seasonal anabranches. Each island forms the core of one or more large compound bars. 'Bar' is defined following the American Society of Civeil Engineers Task Force (1966) as a bedform with length of the same order of magnitude as the channel width and height comparable to the depth of the generating flow. 'Compound' reflects development by a succession of depositional and erosional events that are partially recorded in bar morphology and sedimentology. As stage falls, higher, shallow channels are drained and extensive gravelly deposits are exposed. In wide, shallow reaches where one or more perennial channels and/or smaller bar-top channels dissect these deposits, the river planform is characterised by low-order braiding that can persist to near-bankfull flows. Elsewhere, in relatively narrow, confined reaches, braiding may never be apparent, even during low flows.

Desloges and Church (1987) and McLean et al. (1999) suggest that wandering is associated with moderate and episodic movement of coarse bed material in association with local channel realignments and the propagation downstream of resulting disturbances. Best current estimates, based on detailed sediment budgeting, are that approximately $3 \times 10^{5} \mathrm{~m}^{3}$ of gravel and sand are introduced into and deposited along the lower Fraser gravel reach annually (Church et al., 2001). The amount that is displaced as bars shift position and channel edges are eroded is much higher (approximately $1.1 \mathrm{Mm}^{3} \mathrm{a}^{-1}$ ). Direct measurements of sediment transport at Agassiz (McLean et al., 1999) indicate that significant bedload transport begins at a discharge of approximately $5000 \mathrm{~m}^{3} \mathrm{~s}^{-1}$, and ranges from $1 \times 10^{2} \mathrm{tday}^{-1}$ to $1 \times 10^{4} \mathrm{t}_{\text {day }}{ }^{-1}$ (specific fluxes of between 0.002 and $0.23 \mathrm{~kg} \mathrm{~s}^{-1}$ ).

\section{DATA COLLECTION AND ANALYSIS}

The earliest reliable survey of the river is a topographical survey of 1912, while air photography - mostly obtained at low flow - is available from 1928. After 1949, the frequency of photography is approximately every 5 years. These sources form the basis for a historical perspective of bar development. Detailed bathymetric surveys are available from 1952, 1984, 1999 and 2003 and form the basis for calculation of the bed material sediment budget of the reach (Church et al., 2001; Ham, 2005) using the so-called morphological method (Ashmore and Church, 1998). The budget is established in 1-km increments along the channel, so the sediment balance can be resolved in the vicinity of two individual study bars.

These results are supplemented by GPR stratigraphy on the study bars which permits a more detailed reconstruction of their $20^{\text {th }}$ century development. The shallow subsurface stratigraphy was examined using a Sensors and Software pulseEKKO ${ }^{\text {TM }}$ IV system with a $400 \mathrm{~V}$ transmitter and three different antennae, rated at 50, 100 and $200 \mathrm{MHz}$. The high frequency 
antenna provides greater resolution but less penetration depth. Signal wavelength $(\lambda)$ was 1.7 , 0.85 and $0.43 \mathrm{~m}$ respectively, for the three antennae, and achieved resolution fell between $\lambda / 2$ and $\lambda / 3$. Penetration depths were 25,15 and $10 \mathrm{~m}$ respectively. An introduction to gravel-bed radar stratigraphy and a discussion of the data analysis procedures are given in Wooldridge and Hickin (2005). The surveys were conducted in October 2000.

In 1999 geomorphological maps of each bar in the gravel reach were constructed from field investigations and aerial photography. Detailed topographic surveys of two bars, Calamity Bar and parts of Queens Bar (Figure 2) were completed using a total station on several occasions between April 2000 and December 2003. Some changes occurred on Queens Bar in the freshet of 2000 and significant changes occurred on both bars during the 2002 freshet (instantaneous peak flow, $11300 \mathrm{~m}^{3} \mathrm{~s}^{-1} ; 50$ days with flows above $7000 \mathrm{~m}^{3} \mathrm{~s}^{-1}$ ) but the modest floods of 2001 and 2003 had little impact on either bar. Surveys in April and September 2000 and in March 2002 and December 2003 therefore bracket the significant floods on Queens Bar while surveys in March 2002 and April 2003 captured the major changes on Calamity Bar. On both bars, quasi-systematic grid sampling within individual morphological units was augmented by careful delineation, at shorter point spacing, of important breaks of slope. Floodplain and island edges were included in the surveys but island cores were not sampled and positions inundated by more than $0.5 \mathrm{~m}$ of water at the time of survey were also excluded.

The surveys on Queens and Calamity Bars covered approximately $0.37 \mathrm{~km}^{2}$ and $0.19 \mathrm{~km}^{2}$, respectively, with an average sampling density of 0.01 points $\mathrm{m}^{-2}$. Lower sampling densities on featureless planar areas contrast with densities of up to 0.2 points $\mathrm{m}^{-2}$ in areas of intricate topography (Figure 2). Typical survey errors were established for individual point coordinates using a propagation of variance approach. Depending on position, 95\% confidence limits range between \pm 4 and $12 \mathrm{~mm}, \pm 4$ and $24 \mathrm{~mm}$ and \pm 4 and $18 \mathrm{~mm}$ in $\mathrm{x}, \mathrm{y}$ and $\mathrm{z}$, respectively. Average confidence limits across the whole site are $\pm 10 \mathrm{~mm}$ in $\mathrm{x}, \mathrm{y}$, and $\mathrm{z}$. Grid-based digitial elevation models (DEMs) with $1 \mathrm{~m}$ spacing were created from the irregular survey data by linear interpolation of triangular irregular networks. Tessellation of triangulated irregular networks (TINs) introduces interpolation errors but was necessary in order to make use of raster mapping and analysis tools (McCullagh, 1998; Brasington et al., 2000). Residual errors (the differences between measured and modelled elevations) were, however, very small. For example, 95\% of point elevations measured during the Calamity survey of April 2000 are within $\pm 2 \mathrm{~mm}$ of the DEM elevations at the corresponding planimetric positions. This outcome confirms results of Ham (2005), who conducted an exhaustive comparison of alternative mapping and interpolation methods and similarly arrived at the conclusion that tesselation of an initial TIN provided an efficient surface model of high precision. Ham used explicitly defined breaklines (e.g. Brasington et al., 2000). Triangulation was not constrained by breaklines in our study because visual inspection indicated that triangles rarely crossed well-defined breaks of slope. Indeed, points were measured along the tops and bottoms of all slopes of interest, ensuring that their topography was represented in the model. Testing on complex, stepped areas demonstrated no significant improvement in the average residual error when explicit break-lines were included.

The overall precision of DEM elevation estimates is significant given our interest in morphological change. Consideration of both surveying and modelling errors suggests that individual DEM elevations have a precision of approximately $\pm 12 \mathrm{~mm}$, which is very small relative to bar topography and substantially less than the noise associated with surface texture, i.e. the positioning of the target pole relative to grain tops and interstices $\left(\mathrm{D}_{50}\right.$ on Queens bar is $28 \mathrm{~mm}$ and on Calamity is $31 \mathrm{~mm}$ ). For example, in the Calamity survey of April 2000, 12 $\mathrm{mm}$ represents $0.25 \%$ of the elevation range measured during the survey and approximately half of a median grain diameter. In general, we assume that combined survey and DEM- 
generation errors are less than the errors introduced by surface texture and, when comparing DEM surfaces for topographic change, we use $\pm 2 \mathrm{D}_{50}(= \pm 55 \mathrm{~mm}$ on Queens and $\pm 61 \mathrm{~mm}$ on Calamity) as the minimum detectable vertical difference. This ensures very conservative estimates of change.

\section{BAR TYPOLOGY}

\section{Compound Bar Styles}

At the reach scale, sediment accumulations alternate about the principal sinuous channel (Figure 3A) in a manner analogous to that described previously in smaller rivers (Lewin, 1976; Bluck, 1976; Ferguson and Werrity, 1983). The fundamental morphological unit is the familiar pool-riffle-bar triplet: deposition grows a bar where flow diverges on the back of an oblique riffle, while scour creates a pool that is constrained by the facing bank where flow converges below the riffle front (Figure 3B, C). The organisation of sediment storage in Fraser River is therefore similar to that in smaller, single-thread channels despite its larger scale and distinctive wandering morphology.

Individual bar platforms develop through varied histories of cumulative sediment deposition, stabilisation and reworking but the resulting compound bars exhibit a limited range of morphological styles. The majority share features with the lateral bars described by Church and Jones (1982), Ferguson and Werrity (1983) and Forbes (Forbes, 1983), and are equivalent to the Type 3 lateral bars described by Bluck (1976) and the bank-attached compound bars described by Brierley (1991). They are seasonally attached accumulations that separate the perennial, principal channel, which conveys the greatest volume of water and contains the talweg, from a secondary channel that runs between the bar and the floodplain edge (Figures 4A, B). Lateral accretion is common along the principal channel so that the outer bar face tends to grow toward the opposite bank, causing compensatory erosion. The secondary channel (referred to as an inner- or chute-channel on smaller rivers) conveys substantial discharge during the freshet but during low flow is proximally disconnected from the principal channel by bar-head attachment to the adjacent channel bank. At low flows, distal connection to the principal channel usually maintains a backwater slough. One or more islands at the height of the floodplain form the core of each supra-platform and are separated and trimmed by seasonally active anabranches (also referred to as 'summer channels'). At moderate to high flows these direct water from the principal into the secondary channel. Mobilised gravels may be deposited at the distal ends of the anabranches, promoting downstream growth of the inner bar face and secondary channel widening by erosion of the attached bank. Variations in gross morphology reflect the width of the active belt and the sinuosity of the principal channel (Bluck, 1976). More elongate morphologies like Queens (Figure 4A), Carey, and Powerline Bars occur in straighter, relatively narrow reaches, while more compact versions like Hamilton (Figure 4B), Lower Herrling and Tranmer Bars are associated with wider more sinuous reaches.

Compound medial bars are mid-channel, detached, rhomboid forms with two sub-equal perennial channels that split around the channel head and rejoin at the bar tail, as at Spring Bar (Figure 4C). Accretion at the bar-head means that the bar grows upstream away from the stable island in the centre of the platform. Deposition is also apparent on the downstream flanks of the island core. The bar tail is trimmed by the flanking channels and both outside banks are steep and erosional. Spring Bar is located in the upstream, steeper section of the gravel reach, consistent with observations about medial bars noted by Bluck (1976) and Church and Jones (1982). 
Several previous bar typologies for gravel-bed rivers have recognised a third style - diagonal bars (Church and Jones, 1982; Ferguson and Werrity, 1983). They are elongate, asymmetric forms where the leading edge of the bar platform obliquely crosses the width of the channel and is attached to the floodplain banks at both ends. Several essentially parallel, perennial channels dissect the bar platform into a string of remnants between steep riffles. Although diagonal bars exist at smaller scales as a style of unit bar (see below), compound bars with this form are not apparent on Fraser River. Analogous larger-scale features, comprising two or three compound bars are apparent, however, at the scale of the whole reach where there is a tendency for sedimentation to persist on decadal timescales along major diagonal axes fixed by the overall alignment of the channel (Ham, 2005). That alignment, in turn, is set by the adjacent mountain slopes and certain Pleistocene sedimentary features. The sequence of bars, Queens - Wellington - Webster is an example that stretches obliquely across the river for a distance of approximately $9 \mathrm{~km}$ (Figure 3 ).

\section{Primary Unit Bars}

The depositional morphology exposed during low flow indicates that areally extensive but relatively thin gravelly sheets are important transport features. These migrating bedload sheets (cf. Hein and Walker, 1977, "diffuse gravel sheets"; Whiting et al., 1988) consist of gravel and sand, one to three coarse grain-diameters (up to $0.15 \mathrm{~m}$ ) thick and can have a leading edge defined by a clear topographic break and change in grain size (Figure 5A, B) or a diffuse front characterised by dispersal of particles amongst the fabric of the underlying unit (Figure 5C). The sheets are usually lobate in plan form with curved lateral edges that become topographically and sedimentologically indistinct with distance from the leading edge. Such sheets have been widely observed in the field where moderately to poorly sorted gravel-sand mixtures are in transport (Gustavson, 1978; Prestegaard, 1987; Whiting et al., 1988; Dinehart, 1992; Lunt et al., 2004).

Bedload sheets contrast with thicker units possessing a distinct, leading-edge avalanche face that can vary in height from a few tens of centimetres to more than a metre (Figure 5D, E). Behind the avalanche face is an extensive horizontal or low-angle, stoss-side platform (Figure 5F) upon which sheets are often observed. Sheets are not observed downstream of slip faces suggesting that the larger units develop by vertical and slip-face accretion as sheets stall and (or) dissipate on the stoss-side platform or are destroyed upon reaching the slip face. This is consistent with earlier field interpretations (Hein and Walker, 1977; Bluck, 1982), direct field observations (Whiting et al., 1988; Dinehart, 1992) and laboratory observations in which sheets overtook one another (Ashmore, 1991) to build low-relief bedforms (Livesey et al., 1998). Following Ashley (1990) these bedforms are best described as unit bars (Smith, 1974) because they are solitary, in-channel bodies that have simple depositional histories controlled by local flow and sediment supply conditions.

Compound bars grow by the accretion of primary unit bars at places where flow diverges or where depth is otherwise reduced and relative roughness increases: along bar edges, at bar heads or in the upstream openings to secondary channels and seasonal anabranches. Each setting produces a distinctive morphology.

(i) In general we use the term flank bar to describe any unit bar that attaches to the flank of a compound bar including elongated (Figure 6A; 1, Figure 7A), crescentic (Figure 6B) and lozenge-shaped, compact versions (2, Figure 7B). Flank bars form where drag retards the downstream progress of one side of a mobile unit bar so that a strong asymmetry develops as the leading slip-face swings around to face into the bar core. The lee face thus becomes aligned subparallel to the main flow and the stoss slope grades gently upstream and offshore. In the elongated example along the flank of Queens Bar (1, Figure 7A) two stacked flank-bar 
units are clear (A-A'). They are similar to the point unit bars of Smith's original classification (Smith, 1974) but they do not always form in curved channels (Figure 6A) and can attach to compound bars that form the outside edge of a bend (Figure 7, inset). In channel bends where there is strong secondary circulation they take on a crescentic shape but, unlike the scroll bars described by Lunt et al. (2004), they are not always associated with bar tails and can form upstream of a bend apex (Figure 6B). In general, the range of settings mean that it is not appropriate to associate them with the scroll bars that wrap around bends in meandering channels (the original sedimentological usage) and their often compact shape is not usefully described by the term scroll, "of roll form".

(ii) Transverse unit bars are as described in Smith (1974) - typically broad and lobate (convex, looking from downstream), with a distal avalanche face and an extensive, low-angle stoss-side platform. They form in the upstream bed of secondary and summer channels when sheets and bars moving out of the principal channel encounter shallower flows and stall. The "tongue-shaped anabranch entrance bars" of Burge (2006) are equivalent.

(iii) The third style develops where a mobile unit bar encounters an island or low-lying bar head that divides the flow. Deposition occurs first at the apex of the bifurcation and then progressively farther downstream on the flanks of each channel so that the unit stalls and wraps around the bar head. The leading edge of each such bar-head unit bar is therefore concave looking from downstream (Figure 6C) and resembles a chevron pointing upstream (Figure 6D). On Queens Bar a large unit bar wraps around the head of the central island (3, Figure 7A) burying the underlying, vegetated surface to a depth of up to $2 \mathrm{~m}$ (Figure 5E). Successive unit bars extend island heads upstream. Burge (2006) identifies such bar-head bars as an important element of anabranching dynamics in wandering gravel-bed rivers.

\section{Secondary Unit Bars}

Reworking of primary unit bars produces new sheets and thence secondary unit bars within secondary channels and seasonal anabranches. These can be simple, isolated bars, as in the secondary channel at Calamity Bar (4, Figure 7B), or more complex arrangements where deposition leads to flow bifurcation and the propagation, stacking and interaction of new chute-lobe couplets downstream. For example, the transverse unit bar in the centre of the seasonal anabranch on Queens Bar (5, Figure 7A) splits the flow into two channels. We refer to these within-anabranch channels as bar-top channels. Headward erosion in both of them (6, Figure 7A) yields mobile gravel units that stall where flow diverges across the front of the parent body. These units overlap one another promoting complex patterns of flow divergence and convergence that cause local scour, dissection and deposition and a stepped morphology of stacked unit bars, unit-bar remnants, scour holes and erosional bar-top channels (D-D'-D', Figure 7A). Similar chute-lobe morphologies have been described in a variety of gravel-bed, predominantly braided, rivers (Smith, 1974; Bluck, 1976; Hein and Walker, 1977; Martini, 1977; Gustavson, 1978; Southard et al., 1984; Ashworth et al., 1992; Ferguson et al., 1992; Germanoski, 2001; Lunt et al., 2004).

Secondary unit bars can be classified by their morphology and setting as transverse (7, Figure 7A) or diagonal (as described above), longitudinal where they are lobate, isolated slugs within bar-top channels (8, Figure 7A), or mouth bars where the unit is an elongated, deltalike extension into deeper water of the bar-top channel that feeds it (9, Figure 7A; 4, Figure 7B). This terminology replicates Smith's original typology, with the addition of the mouth bar type that is similar to 'tributary mouth bar' (e.g. Lunt et al., 2004) but avoids confusion with the bars found in flow separation zones at river channel confluences.

The area of secondary unit bars tends to increase with increasing elevation above low water, indicating that progressively smaller bars are produced as flow stage drops and the flow is 
constrained within channels delimited by the edges of higher order bars or higher-stage incisions. At the smallest scales the avalanche faces of both primary and secondary unit bars are dissected by small grooves during the falling limb of the hydrograph (Figure 8A, B). These slip-face grooves yield the smallest unit bars of the hierarchy, extending out from the bar front as a straight or bulbous tongue with an arcuate tip and an upper surface that can be horizontal or have an axial depression. We refer to these as slip-face lobes, a term that is similar to several descriptors previously applied to these features, none of which have gained consensus use ('delta lobes' (Collinson, 1970), 'transverse deltas' (Bluck, 1979) 'lobate deltas', 'delta bars' or simply, 'depositional lobes' (Lunt et al., 2004)), which more accurately describes their typical setting and distinguishes them from larger delta-like mouth bars. Large numbers of these features occur along the avalanche faces and riffle fronts associated with all types of primary and secondary unit bars.

\section{Bar and channel typology}

The hierarchical typology of channels and bars described above is summarised in Figure 9 in which the planimetric area of bar and channel features decreases from top to bottom. The values on the left provide an approximate length scale in metres and the values in parentheses express this as multiples of the average width of the principal channel. Horizontal alignment in the figure associates bars with the channels where they form. The arrows indicate that primary and secondary unit bars occur at a range of scales in association with several channel types. For comparison, Bridge and Lunt (2006; Figure 4) provide an indication of the dimensionless bedform geometries associated with compound bars, unit bars and gravel sheets. Unit bars are the key dynamic element in bar construction linking sediment transport by gravel bedload sheets to the long-term morphological evolution of the compound bars. Bedload sheets are the primary building blocks of unit bars and occur across the full range of spatial scales.

The typology introduces two new terms ("flank unit bar" and "slip-face lobe"), one modified term ("mouth bar"), and distinguishes between "primary" and "secondary" unit bars. Terminology for the unambiguous and consistent description of barforms remains elusive and we understand that proliferation of descriptors can be unhelpful (cf. Smith, 1978; Ashmore, 1982). However, we have suggested new terms after careful consideration and explained our rationale in each case. For the most part our typology uses what are emerging as consensus descriptors for coarse-grained, laterally unstable gravel-bed settings with additions and modifications only where this is necessary to more exactly describe the form or setting within the wandering style. This typology is presented as a model that can be evaluated on other rivers. Our own experience from other wandering rivers (e.g. Desloges and Church, 1987; Rice and Church, 1998; Wooldridge and Hickin, 2005), and existing descriptions from other authors (e.g. Ferguson and Werrity, 1983; Burge, 2006) indicate that this is a robust and widely applicable typology.

\section{COMPOUND BAR DEVELOPMENT AND CHANGE}

\section{Inter-annual development of bars}

We have investigated the volume and pattern of sedimentation on Calamity Bar and part of Queens Bar between 1999 and 2003. The freshet of 2000 caused small-scale reworking in the main summer anabranch on Queens Bar. This included headward erosion of the two bar-top channels (1, Figure 10A), consequent deposition of unit bars in the right-hand channel (2) and extension of the mouth unit bar downstream of the left-hand channel (3). Erosion of the upper 
bar edge (4) was associated with distal extension, without vertical growth, of the main flank bar unit (5).

The freshet of 2002 caused more substantial morphological changes. A primary transverse unit bar moved into the main anabranch partially filling both bar-top channels (6, Figure 10B) and forcing significant erosion of the older bar-head unit to the south (7) and the island to the north (9). Displaced material reduced conveyance in the distal part of the left-hand bar-top channel forcing significant erosion of the channel's right bank (8).. Realignment of the bartop channels in response to deposition of the large unit bar maintained the capacity of the anabranch to take water from the principal channel. Substantial erosion occurred along the principal channel edge (10) and across large parts of the flank unit bar. Displaced material was transported laterally and distally, extending the tip of the unit by approximately $200 \mathrm{~m}$ and completely filling the adjacent back-water (11).

The 2002 freshet also caused significant morphological change on Calamity Bar, most prominantly the primary accretion of a compact flank bar (1, Figure 11). The new unit mimics the shape of the earlier unit that it overrides, indicating that recent patterns of flow and sediment transport have not significantly changed. A longitudinal unit bar formed in the downstream reach of the secondary channel in response to proximal reworking of the channel bed (2).

DEMs of difference provide estimates of the areal extent of reworking and of volumetric change on these bars during individual freshets (Table 1). Estimates are for net cut and fill in excess of the minimum detectable difference and are minimum, conservative estimates given the use of $2 \mathrm{D}_{50}$ as the minimum detectable change. Even in the moderate freshet of $2000,70 \%$ of the common survey area of Queens was subject to some net cut or fill with mean values of -0.30 and $+0.33 \mathrm{~m}$, respectively. In the larger freshet, $89 \%$ of the area experienced net change in elevation, mean cut and fill values were greater $(-0.81$ and $+0.68 \mathrm{~m})$ and approximately $5 \%$ of elevation changes were in excess of $2 \mathrm{~m}$. In 2002, the total volume of material deposited at sites that experienced net fill was $142463 \mathrm{~m}^{3}$, and the total volume of material lost from sites where there was net cut was $82267 \mathrm{~m}^{3}$. If all of the cut material remained on the bar, contributing to the total net fill figure, the difference $\left(60196 \mathrm{~m}^{3}\right)$ must have been added to the bar by primary accretion. In fact, it is almost certain that a proportion of the total cut volume was lost from the bar and, therefore, that $60196 \mathrm{~m}^{3}$, represents a minimum estimate of primary accretion during the 2002 freshet. A smaller minimum net gain of $13060 \mathrm{~m}^{3}$ occurred during the 2000 freshet on Queens and on Calamity Bar the minimum net gain during the 2002 freshet was $24471 \mathrm{~m}^{3}$.

\section{Historical development of the compound bars}

Over many seasons, the addition of unit bars, local erosion, channel shifting and avulsion create the large, compound bars that are the visually dominant morphological elements of the river. They become complex sedimentary accumulations because, as the bar develops, it influences the orientation of the river currents, directing further accretion and erosion in irregular ways. We have studied these cumulative processes using the air photo record. We contrast the development of an apparently simple lateral bar (Calamity Bar) with the recent development of an old-established bar-island complex (Queens Bar).

Whilst the contemporary morphology of Calamity Bar gives the appearance of a straightforward sequence of laterally stacked unit bars, the actual history of the site is more complex (Figure 12). In 1938, the configuration of the main channel was similar to that today but a short-lived realignment of Fraser River in the 1940s forced clearwater discharge from Harrison River against the site (Figure 13 A, B). The bar was trimmed back, to leave a residual bar protected by the bedrock of Harrison Knob behind it. Significant net deposition 
resumed at the site only after the river adopted its current alignment in the 1970s (Figure 13 C, D). A sequence of laterally accreted, compact, flank bars has built the contemporary compound bar which remains relatively small and is effectively about 35 years old. Its lateral growth has promoted significant erosion on the left bank of the river, resulting in the establishment, since 1990, of a new lateral bar about $2 \mathrm{~km}$ downstream on the left bank (N Bar, Figure 1).

Queens Bar is the upstream anchor of an extended sequence of bars that is aligned diagonally across the river and stretches downstream for about $9 \mathrm{~km}$ (Figure 3); a feature that has been present in the river since the first survey in 1877-85 (see North and Teversham, 1984). In 1938, an established bar-island, protected from the main river by a rocky promontory upstream, was separated from the active bar by a perennial channel (Figure 14). Sedimentation through the 1940s, culminating in the flood of record in 1948, filled that channel and added two substantial lateral units to the bar. Backwaters behind these flank units filled and, after 1960, the bar stabilized for a period of approximately 30 years. After 1990, the development of $\mathrm{N}$ Bar on the left bank of the river (sixth map in Figure 14, $20^{\text {th }}$ March 1999) forced erosion of the upper part of Queens Bar. Sediment mobilised by this action mainly travelled along Queens Bar and deposited as new flank bars downstream. This activity continues to present, with compensating erosion occurring on the left bank opposite the point of accretion. Some of the sediment liberated from the head of Queens, has been deposited as large transverse unit bars in the main seasonal anabranch (the former perennial channel noted above), leading to the complex unit bar assemblages described earlier in the paper. Vegetation has become established on the highest portions of the main bar since 1970, trapping sand and establishing four new island units.

Quantitative understanding of the long-term evolution of these two bars was obtained by constructing their long-term sediment budgets. This is possible using repeated river bathymetric surveys from 1952, 1999 and 2003 (Ham, 2005). The latter interval encompasses the period of our detailed annual surveys. For volumetric calculation, each bar was assigned a base elevation equal to the elevation at which the stream bed adjacent to the bar began to slope upward toward the bar. This elevation was, in each case, within $0.5 \mathrm{~m}$ of the contemporary talweg elevation. Table 2 presents results both for each bar and for the bar plus the adjacent channel, that is, for the entire river channel zone for the distance defined by the length of the bar.

Comparing the field survey estimates (Table 1) with the bar-only sediment budget, it is apparent that the long-term pattern of sediment exchange differs from that recorded by our annual field surveys, which were restricted to the exposed bar surface and, at Queens Bar, focused on the observed accretionary units. Overall, the period 1999-2003 was a period of net loss from both bars. The net loss is very small at Calamity, but at Queens Bar it is large and the reason for it is erosion near the bar head where the river is being pushed to the right by the growth of N Bar (Figure 14). The longer term sediment budget (1952-1999) reveals growth at both bars that is of the same order of magnitude as the overall rate of sediment mobilization along the river. Errors associated with these estimates fall within the range $1-10 \%$ (see Table 2)

Comparing the entire channel zone in the vicinity of the bars reveals a considerably different picture. At Calamity Bar, there is significant long-term growth, most of it focused on the bar, although between 1999 and 2003 substantial sedimentation occurred in the channel. At Queens Bar, the net sediment balance in this recent period is strongly negative, indicating that the sum of material removed from the bar head and from the left bank of the river opposite the new flank bars (Figure 14) more than compensates the net sediment deposition on the bar. 
The net budget over the entire period is essentially in balance. That is specifically because lateral instability of the channel in the vicinity of Queens Bar commenced only after about 1990, with the development of N Bar - prompted by events upstream at Calamity Bar. Errors of these estimates ranges up to $25 \%$, except for the long-term estimate at Queens Bar, where the change lies within the error bound. This long-term sediment balance indicates a mature bar essentially at equilibrium with the river processes. Between 1984 and 1999, net accretion was about $10000 \mathrm{~m}^{3} \mathrm{a}^{-1}$.

\section{RADAR STRATIGRAPHY}

\section{Introduction: radar units}

The outcome of the processes we have described is production of a fluvial macroform (Jackson, 1975), the sedimentary body that is associated with the observed compound bar morphology. We have sampled the macroform stratigraphy using ground penetrating radar so that its description remains inherently interpretive, hinging as it does on the recognition of bounding surfaces and bedding in the radar images. In Fraser River, a limited number of radar facies was found to characterise the macroform compound bars. The sequence of radar signatures utilised here was introduced by Wooldridge and Hickin (2005) on the basis of studies at sites in several rivers. (They identified facies not present in the bars presently under study but we have retained their original numbering for consistency so, for example, there is no radar facies 4 described here.)

Radar facies 1: subhorizontal, subparallel, continuous reflections consist of stacked, 3 to $5 \mathrm{~m}$ thick traces, which can be traced in both flow-parallel $(30$ to $100 \mathrm{~m})$ and flow-normal directions. It occurs as discrete packages and also grades into or out of other facies. The facies is interpreted as stacks of vertically accreted bedload sheets moving onto bar surfaces and into secondary channels. The subparallel nature of the radar signal is probably due to successive sheets overtaking and burying previously stalled sheets.

Radar facies 2: low-angle cross-stream dipping, subparallel reflections occur in 3 to $8 \mathrm{~m}$ thick, stacked, continuous $(>150 \mathrm{~m})$, gently inclined ( 3 to $6^{\circ}$, occasionally to $14^{\circ}$ but declining with depth) subparallel traces dipping normal to the flow. The flow-parallel character is horizontal to subhorizontal reflections. The interpretation is lateral accretion deposits constructed from successive bedload sheets. The reduction in dip angles records the transition from sediment avalanching over bar-margin slipfaces to bedload sheets migrating along inboard, lower-angle channels. The steeper dipping reflections occur in proximal positions. There is little evidence of reactivation surfaces, suggesting a conformable deposition history that has both vertically and laterally extended the bar.

Radar facies 3: low-angle downstream dipping, subparallel reflections consist of divergent to subparallel reflections, 0.5 to $7 \mathrm{~m}$ thick, that dip downflow (4 to $8^{\circ}$ ) in continuous sets $(40$ to $>200 \mathrm{~m}$ ), occurring in both flow-normal and flow-parallel orientations. The flow-normal signature includes both hummocky and subhorizontal reflections. The signature is interpreted as bar-margin slipface sediments documenting the migration of bedload sheets over the bar margin into deeper water at high flow, causing the barform to aggrade and translate downstream and/or laterally. The dip angle tends to decline downstream because reflections diverge as the barform progrades into the deeper water. The hummocky features are interpreted to indicate locally variable sediment transport creating lobe-like deposits.

Radar facies 5: small to medium scale, steeply inclined oblique reflections exhibits continuous sets ( 10 to $90 \mathrm{~m}$ ) of 0.5 to $3 \mathrm{~m}$ thick, parallel to subparallel, steeply inclined (16 to $26^{\circ}$ ), oblique reflections. The signature is interpreted as bar margin slipface deposits where 
sediments have avalanched over high relief margins into deeper water. The smaller-scale reflections may indicate the depositional signature of individual unit bars. Also hummocky reflections, interpreted as prograding bedload tongues in deeper water.

Radar element I: basal, concave-up reflections truncate adjacent reflections and are typically filled with subhorizontal and concave-up reflections. The element extends 35 to $45 \mathrm{~m}$ laterally with relief between 2 and $2.5 \mathrm{~m}$ at the inner channel site on Queen's Bar. It is restricted to the middle and upper portions of the channel. The signature is interpreted as an element (not a facies) indicating scour of secondary channels and chutes. The basal reflection is infilled by a variety of reflections that make up the subsequent channel fill.

\section{Calamity Bar radar stratigraphy}

Firstly, the stratigraphy and evident structure of an apparently simple lateral bar that has been actively building by the successive attachment of primary unit bars since the 1970s is considered. A radar cross-section at mid-bar is shown in Figure 15. The stratigraphy is split by a prominent subhorizontal reflection about $8 \mathrm{~m}$ below the bar surface that is inferred to represent the depth of scour in the most recent degradational phase after 1943 (see Figure 13). The radar images of the deeper sediments (storey 1; Figure 15) are not well-defined. Hummocky reflections (facies 3) surround a set of steeply inclined reflections dipping southsoutheast (facies 5). The hummocks may represent intertonguing gravelly lobes but their genesis is uncertain. The steeply inclined reflections indicate a steep bar margin prograding toward the channel and are opposite to those in the upper storey.

The upper storey (storey 2) is dominated by extensive low-angle, southerly dipping reflections (facies 2) that are characteristic of lateral accretion and point bar sedimentation. The 1952 bathymetry defines a channel bed that exhibits some hummocky reflections (facies 5 ) and then roughly coincides with the upper bounding surface of steeply dipping reflections prograding toward the northern channel margin. This suggests that these facies likely were deposited prior to 1952, when the talweg impinged on the bar (Figure 13b). It is of course possible that the deposits post-date 1952, following scour of the 1952 bed. The 1952 bed is about $5 \mathrm{~m}$ below the present bar surface, coincident with the estimated thickness of the contemporary bar deposit, which is $4.9 \mathrm{~m}$.

The shift in style of deposition from slipface to lateral accretion within the storey was produced by a change in flow direction across the bar after 1971 (Figure 12), by which time flow was directed away from the bar rather than toward or directly over it. The new style of sedimentation saw bedload sheets onlapping the slipface deposits causing episodic lateral and downstream growth of the bar. This style is recorded by the 1984 bathymetric surface, which is positioned in the midst of the lateral accretion deposits. The scale of these deposits is comparable with the depth of the channel in which they are formed. There are few reactivation surfaces suggesting little scour during the deposition of onlapping sheets. The post-1971 change in sedimentation style marked the inception of the rapid lateral growth of Calamity Bar (Figure 12) and the change in flow pattern may, in part, have been prompted by the surface elevation achieved by the bar at that time.

Figure 16 gives a generalized composite view of all the radar lines available on Calamity Bar (see figure 12 for line positions). The underlying bar platform largely consists of radar facies 5 , interpreted to be prograding bedload sheets or tongues in relatively deep water. This is surmounted by offlap and channel fill deposits exhibiting radar facies 2 and 3, while the topmost deposits of high floods onto the mature bar are bedload sheets of radar facies 1 . The pattern is not invariable and substantial complications occur where summer channels have been cut and filled across the bar. 


\section{Queen's Bar radar stratigraphy}

We present stratigraphic investigations from three sites on the much larger and more complex Queen's Bar. At a site in the major summer (secondary) channel (see Figure 14 for location), the radar stratigraphy records the serial nature of channel infilling (Figure 17a). The architecture is divided into two sedimentary packages by a subhorizontal reflection about $7 \mathrm{~m}$ below the surface of the bar. Storey 1 exhibits concave-up forms (radar element I) truncating subhorizontal reflections, which likely indicate the development of a chute at the site. The chute appears to have been filled by successive sheets aggraded in place as they actively conveyed sediment. The stratigraphic interval is interpreted as a storey because of the thickness of the sediments and the laterally continuous nature of the bounding surface.

Storey 2 exhibits two styles of sedimentation interpreted to be growth increments (substoreys $2 \mathrm{a}$ and $2 \mathrm{~b}$ ) in the infilling of the channel. The lower interval documents steeply inclined reflections (facies 5) grading into lower angled reflections (facies 2). The stratal configuration probably reflects sediment avalanching northwest over high relief bar margins, and then onward traction transport over a lower-angled margin. The decline in dip angle may be related to sedimentation in-channel, away from the bar edge. The distinct terminations of the lowerangled downlapping reflections imply that the strata were deposited by flow-normal directed sediment transport continuing to pass over the bar crest.

The upper growth interval (storey $2 \mathrm{~b}$ ) shows very similar reflection configurations and facies juxtapositions as those found in storey 1 . The depositional history is proposed to be nearly equivalent to that of the lower storey, except the style of chute-infilling differs. Instead of concave-up (parallel to form) reflections, the chute is infilled with subhorizontal reflections, indicating that transport was not confined within the chute but rather that bedload sheets buried the chute. The architecture in storey $2 \mathrm{~b}$ is largely coincident with the recent photographic record and surveys (see Figure 10), in which a slug of sediment is seen to be migrating down the former channel and terminating in a $2.5 \mathrm{~m}$ high slipface. Figure $17 \mathrm{~B}$, a flow-parallel transect, shows pronounced medium-scale, steeply inclined reflections (facies 5) which were deposited on the front margin of the sediment slug. The front appears to have moved $9 \mathrm{~m}$ between 1999 and 2000, then $65 \mathrm{~m}$ in 2001, when much smaller-scale inclined reflections appeared.

The contemporary bar is estimated to be about $4.7 \mathrm{~m}$ thick, corresponding with storey $2 \mathrm{~b}$. The multi-storey stratigraphy, with multiple internal scour surfaces, supports morphological observations that former channels do not fill in a simple fashion, but are episodically filled by successive sediment waves prograding through the channel.

A site on the outer mid-bar (Figure 18; see Figure 17 inset for location) records the former position of a series of bar-margin slipfaces. The simple architecture is characterised by two radar facies that repeat in the vertical successions above and below a distinct subhorizontal reflection $\sim 10 \mathrm{~m}$ below the bar surface. The facies terminate at this boundary, defining two genetically unrelated storeys.

Storey 1 shows steeply inclined reflections (facies 5) offlapping subhorizontal reflections (facies 1). This association probably marks the advance of a high relief bar margin over a lower angle bar surface. Storey 2 is dominated by two sets of steeply inclined reflections (facies 5) that also dip westward and trace the position of former bar fronts as they accreted. Scale differences between the two sets are likely due to different autogenic processes depositing sediment in-channel (substorey 2a) and on bartops (substorey 2b). In both cases they interfinger with and are juxtaposed beside subhorizontal reflections (facies 1). Bathymetric soundings indicate $\sim 3 \mathrm{~m}$ of deposition since 1952 , which constitutes a substantial portion of the total thickness of substorey $2 b$ and of the contemporary bar. The style of 
deposition closely matches the unit bar morphology at the site, thus it seems that the sediments record the construction of a unit bar on the site.

Prior to 1952 the site was occupied by the main channel. It is tempting to suggest that the bounding surface, below storey 2 was scoured by the 1948 flood and the larger set of steeply inclined reflections in substorey $2 \mathrm{a}$ is associated with subsequent channel shifting. The geometry of adjacent barforms in 1943 is suggestive of this scenario, which would imply that storey 1 dates from before 1943.

A site near the tail of a recently accreted sediment lobe (see Figure 17 inset for location) highlights internally consistent packages of reflections associated with unit bar deposition (substorey 2b)(Figure 19). In contrast, the deeper stratigraphy (storey 1) is composed of reflections that are altogether different and cannot be traced laterally. Storey 2 consists of two distinct sedimentary bodies separated by a subhorizontal boundary about $5 \mathrm{~m}$ below the bar surface. The lower interval (substorey 2a) is dominated by flow-parallel, downstream dipping, low-angle reflections (facies 3) with dip angles declining downflow. The flow normal signature is somewhat undulatory (figure 19). The reflections appear to document the migration of a number of gravelly sheets descending over the distal margin of a bar onto the channel floor. The depth and scale ( 5 to $7 \mathrm{~m}$ thick) of the downstream accretion facies approaches the depth of flow and likely indicates sedimentation in the basal portion of a bar. In contrast, the shallower depths and smaller scale reflections in substorey $2 b$ are characteristic of bartop sedimentation.

The bounding surface between substoreys $2 \mathrm{a}$ and $2 \mathrm{~b}$ likely was scoured between 1949 and 1984 because the photographic record shows that a small barform that occupied a portion of the site in 1949 was subsequently eroded by 1969 (Figure 12). Bathymetric surveys indicate that between 1984 and 1999 at least 3 m of sediment were deposited.

Substorey $2 \mathrm{~b}$ is composed of sets of steeply inclined reflections (facies 5) that grade into and out of subhorizontal reflections (facies 1). The inclined reflections dip both downflow and crossflow (Figure 19), indicating flow divergence across the bartop enabling the barform to build in both directions. The style of deposition matches the morphological evolution of the site since 1998. The stratigraphy at the western edge of the site is probably equal to the thickness of sediment deposited between 1998 and 2000, when a unit bar overrode the site. This implies that the radar stratigraphy images a complete unit bar.

Wooldridge and Hickin (2005) describe further radar stratigraphies on Wellington Bar, a medial bar immediately downstream from Queen's Bar which, additionally, exhibits lowangle upstream dipping accretion deposits (their radar facies 4) at the bar head, representative of the bar head unit bars described above.

Altogether, the radar facies described in the bars conform well with the styles of sedimentation identified on the surface. Radar facies 1 corresponds with bar-top vertical accretion of unit bars, while facies 2 is the stratigraphic signature of lateral accretion of (mainly) flank unit bars. Facies 3 represents downstream, channel deposited accretion and facies 4 represents upstream bar head accretion. Radar facies 5 consists of bar-margin slipface deposits associated with flank unit bar attachment and channel-bottom lobes of sediment.

\section{DISCUSSION}

On the wandering Fraser River, in keeping with other gravel-bed river styles, compound bars - the mosaic bars of Bluck (1979) or macroforms of Jackson (1975) - are built from unit bars through multiple depositional and erosional events. Unit bars are the key dynamic element in 
bar construction, linking sediment transport in bedload sheets to the long-term morphological evolution of the compound bars via primary accretion from the principal channel and secondary redistribution across the supra-platform. With the passage of time, these processes create a hierarchical agglomeration of barforms and channels (Figure 9).

A similar hierarchical structure is widely acknowledged in braided river models (e.g. Williams and Rust, 1969; Bristow, 1987; Bridge, 1993; Kelly, 2006) with several authors pointing out that scale-invariant morphology is a key property (e.g. Krigstrom, 1962; Paola and Foufoula-Georgiou, 2001; ). Similarly, the styles of accretion and erosion and therefore the major bar-form morphologies on Fraser River are familiar and consistent with bar forms in both gravelly braided channels (e.g., Miall, 1977; Rust and Koster, 1984, Ashworth et al., 1992; Bridge, 1993; Lunt et al., 2004) and single-thread gravelly sinuous channels (e.g., Bluck, 1971, 1976; Lewin, 1976; Martini, 1977; Gustavson, 1978; Jackson, 1978; Forbes, 1983). These similarities are, perhaps, unsurprising because in each case the fundamental process is intermittent movement of coarse bedload, albeit of different relative magnitudes and under different degrees of lateral constraint.

However, just as the wandering planform is distinct from meandering and braided planforms, so the sedimentological features of the wandering style exhibit some distinctive features. We therefore suggest additions to the emerging, consensus terminology for coarse-grained river deposits that are efficient, useful and necessary in order to adequately describe the wandering style ("flank unit bar", "slip-face lobe", "mouth bar"). At the scale of compound bars, lateral forms are most common: medial bars are uncommon. This suggests that one feature of the wandering style that differentiates it from braiding at large scales is the tendency for primary accretion to occur on one side of bar complexes.

Annual topographic surveys reveal that significant primary accretion and secondary reworking take place during individual freshets. Minimum estimates of primary accretion during the 2002 freshet were approximately $60000 \mathrm{~m}^{3}$ for the surveyed portion of Queens Bar and approximately $24500 \mathrm{~m}^{3}$ for Calamity Bar (Table 1). Individual unit bars contribute significantly to these gains. The transverse unit that stalled in the head of the Queens anabranch during the 2002 freshet (approximate boundaries are demarcated in Figure 10B (6)) covers approximately $39400 \mathrm{~m}^{2}$, it has a mean depth of fill of $0.60 \mathrm{~m}$ and its total volume is approximately $23500 \mathrm{~m}^{3}$ or $39 \%$ of the total net volume change. The equivalent figures for the compact flank bar that attached to Calamity in 2002 (Figure 11(1)) are approximately 25 $600 \mathrm{~m}^{2}, 0.70 \mathrm{~m}$ and $17400 \mathrm{~m}^{3}$ or $71 \%$ of the total net volume change. The volumes of these unit bars are consistent with volumes that can be estimated for the Sagavanirktok River (250 $64000 \mathrm{~m}^{3}$ ) using unit bar dimensions given in Lunt et al. (2004).

If the net fill volumes given in Table 1 are distributed over the length of the bars, they yield accretion rates of $28500 \mathrm{~m}^{3} \mathrm{~km}^{-1}$ at Calamity Bar in 2002 and an average rate over the two freshets (2000 and 2002) of $28600 \mathrm{~m}^{3} \mathrm{~km}^{-1}$ at Queens Bar. These figures compare well with volumetric deposition per $\mathrm{km}$ length of channel of $22000 \mathrm{~m}^{3}$ assuming $1.1 \mathrm{Mm}^{3}$ of bed material mobilized, on average, within the $50-\mathrm{km}$ gravel reach in each year (McLean and Church, 1999).

Detailed examination of the historical development (over 65 years) and long-term sediment budgets of two contrasting bars emphasize the major function of the bars as temporary storage points for bed material that is being staged downstream by the river in a sequence of discrete steps. Queens Bar is a large, old-established bar the net budget for which is probably near equilibrium over a period of decades, whereas Calamity is a younger bar that is growing rapidly as the channel migrates away from it. Budgets for only the bar platforms and the platforms plus the adjacent channels reveal different patterns of deposition and erosion that 
highlight the link between accretion on bar platforms and erosion of the opposing bank. The net effect of a linked downstream sequence of unit-bar accretion, opposing bank erosion and downstream deposition of new unit bars, that starts at Calamity and is ongoing downstream of Queens, is to establish a more regular sinuosity through this reach of the river.

These histories also highlight a key difference between the development of compound bars in wandering gravel-bed rivers compared with braided rivers. In rivers like Fraser, some bars are forced, perhaps as part of much larger mega-features as at Queens Bar, by the impingement of the river on the valleyside (particularly, exposed bedrock). Together with the presence of relatively stable vegetated islands, this interaction imparts an overall reduction in dynamism to the river system which is manifest in the longevity of some bars. The 65-year histories shown in Figures 12 and 14 reveal the potential for long sequences of uninterrupted accretion in wandering rivers that are unlikely in braided rivers.

In rivers that maintain a persistent pattern of development over extended periods, such as meandered rivers, the sedimentary macroforms may exhibit sequences of genetically similar facies with replicated sedimentary structures (Miall, 2000) that reflect flow history. In contrast, in dynamic braided channels subject to complex sequences of accretion and dissection on short timescales, the macroform no longer entirely reflects the sequence of formative flows.

On the wandering Fraser River, GPR surveys confirm this to also be the case. Vertical and lateral accretion dominate the major bars, which are palimpsests of unit bars subsequently modified, in section, by the cut and fill histories of the summer channels. Accordingly, surface and subsurface observations are congruent. Further, the recent history of bar accretion recorded in the stratigraphy is consistent with that revealed in historical sequences of photographs. On Calamity bar the lack of stratigraphic complexity within the lateral accretion strata and the limited number of depositional facies in the stratigraphy indicates a relatively consistent style of sedimentation since 1971. The stratigraphic record is, accordingly, consistent with the the photographic record (see Figure 12), which reveals the accretion of successive flank unit bars. The nature of lateral sedimentation, being continuously depositional and unidirectional, allows aggradation rates to be calculated from bathymetric differencing of surfaces (Table 3). The table shows that sedimentation increased after 1984.

There is, however, no single characteristic sequence of sediments in the large compound bars, each of which is clearly influenced by the still larger scale geometry of the river in its vicinity and by the particular local history of the channel and of the bar itself. In contrast, entire unit bars demonstrate equivalence between their surficial morphologies and subsurface stratigraphies, confirming their individually simple depositional histories.

\section{CONCLUSIONS}

Examination of Fraser River bars has produced a typology of bar and channel features for wandering, gravel-bed rivers (Figure 9). This is presented as a model that can be evaluated elsewhere. Our own experience from other wandering rivers (e.g. Desloges and Church, 1987; Rice and Church, 1996; Wooldridge and Hickin, 2005), and published descriptions from other authors (e.g. Ferguson and Werrity, 1983; Burge, 2006) indicate that the typology is robust. The wandering style comprises hierarchies of channels (principal, secondary, seasonal anabranches, bar-top) and sediment storage elements (floodplain, islands, compound bars, unit bars, sheets) that combine to create intricate supra-platform morphologies (Figure 7). A multi-storey architecture is preserved beneath Fraser River that records vertical and lateral accretion of unit bars and their subsequent modification, in section, by cut and fill processes 
in seasonal anabranches and bar-top channels. Unit bars comprised of one or more gravel sheets, are the basic building blocks that record individual sediment transport episodes and dominate the process of morphological change.

We identify primary unit bars as those which deliver sediment to the bar complex from the principal channel and secondary unit bars as those which disperse sediment from the primary accretion sites into and through the bar complex via seasonal anabranches and bar-top channels. Analysis of bar development on decadal timescales makes clear that compound bar formation is controlled by shifts in the position of the principal channel and, therefore, loci of erosion and unit-bar deposition.

Quantitative information from inter-annual topographic surveys, photogrammetric analysis and radar stratigraphy has provided benchmark information about rates of bar growth, sustenance and destruction on a major river undergoing sustained aggradation. These results help address the lack of information that hinders the development of quantitative tools in alluvial sedimentology, including models of alluvial architecture that require validation and development (Bridge, 2003; Lunt et al. 2004).

A major result of this work is demonstration of the critical role that unit bars play in linking the fundamental process of sediment transfer in the river to the production of complex alluvial morphology. This is not a new idea, but it is demonstrated particularly clearly using our longterm data set. While unit bars are created by process, the compound bars are mediated by history.

\section{Acknowledgments}

We thank Darren Ham for furnishing data of the long-term sediment budgets, Jim Chandler for generous technical advice and a host of additional colleagues who made major contributions in the field including Scott Babakaiff, Dave Campbell, Erica Ellis, Tim Johnsen, Nick Manklow, Laura Rempel, Sean Todd, Hamish Weatherley and André Zimmermann. We are also indebted to Sabrina Sasaki, Eric Leinburger and Mark Szegner for their photogrammetric and cartographic contributions. SPR received travel support from the Royal Society and MC, CLW and EJH received funding from the Natural Sciences and Engineering Research Council of Canada. We wish to thank Peter Ashmore and Brian Bluck for detailed and helpful reviews that greatly improved our paper. Finally, it is with great sadness that we record the death our co-author Colin Wooldridge who died while this paper was in review.

\section{REFERENCES}

ASCE Task Force (1966) Nomenclature for bedforms in alluvial channels. Journal Hydraulics Division: American Society of Civil Engineers, 92, 51-64.

Ashley, G.M. (1990) Classification of large-scale subaqueous bedforms: a new look at an old problem. Journal of Sedimentary Petrology, 60, 160-172.

Ashmore, P.E. and Church, M. (1998) Sediment transport and river morphology: a paradigm for study. In: Gravel-Bed Rivers in the Environment (Eds P.C. Klingeman, R.L. Beschta, P.D. Komar and J.B. Bradley), pp. 115-148. Water Resources Publications, Highlands Ranch, Colorado, USA.

Ashmore, P.E. (1992) Discussion of "channel bars in garvel-bed rivers" by M.Church and D. jones. In: Gravel Bed Rivers (Eds R.D. Hey, J.C. Bathurst and C.R. Thorne), pp 326-330. John Wiley and Sons, Chichester.

Ashmore, P.E. (1991) How do gravel-bed rivers braid? Canadian Journal of Earth Sciences, $28,326-341$. 
Ashworth, P.J., Powell, D.M., Prestegaard, K.L., Ferguson, R.I., Ashmore, P.E. and Paola, C. (1992) Measurements in a braided river chute and lobe. 2. Sorting of bed load during entrainment, transport, and deposition. Water Resources Research, 28, 1887-1896.

Bluck, B.J. (1971) Sedimentation in the meandering River Endrick. Scottish Journal of Geology, 7: 93-138.

Bluck, B.J. (1979) Structure of coarse grained braided stream alluvium. Transactions of the Royal Society of Edinburgh, 70, 181-221.

Bluck, B.J. (1982) Texture of gravel bars in braided streams. In: Gravel Bed Rivers (Eds R.D. Hey, J.C. Bathurst and C.R. Thorne), pp. 339-355. John Wiley and Sons Ltd, Chichester.

Bluck, B.J. (1976) Sedimentation in some Scottish rivers of low sinuosity. Transactions of the Royal Society of Edinburgh, 69, 425-455.

Brasington, J., Rumsby, B.T. and McVey, R.A. (2000) Monitoring and modelling morphological change in a braided gravel-bed river using high-resolution GPS-based survey. Earth Surface Processes and Landforms, 25, 973-990.

Bridge, J.S. (1993) The interaction between geometry, water flow, transport and deposition in braided rivers. In: Braided Rivers (Eds J.L. Best and C.S. Bristow) pp. 13-71. Geological Society Special Publication 75.

Bridge, J.S. (2003) River and Floodplains: Forms, Processes, and Sedimentary Record. Blackwell Science, Oxford, UK, 491 pp.

Bridge, J.S. and Lunt I.A. (2006) Depositional models in braided rivers. In: Braided Rivers: Process, Deposits, Ecology and Management (Eds G.H. Sambrook Smith, J.L. Best, C.S. Bristow and G.E. Petts) pp 11-50. IAS Special Publication 36.

Brierley, G.J. (1991) Bar sedimentology of the Squamish River, British Columbia: definition and application of morphostratigraphic units. Journal of Sedimentary Petrology, 61, 211225.

Brierley, G.J. (1989) River planform facies models: the sedimentology of braided, wandering and meandering reaches of the Squamish River, British Columbia. Sedimentary Geology, 61, 17-35.

Bristow, C.S. (1987) Brahmaputra River: channel migration and deposition. In: Recent Developments in Fluvial Sedimentology (Eds F.G. Ethridge, R.M. Flores, and M.D. Harvey) pp 63-74. SEPM Special Publication 39.

Burge, L.M. (2005) Wandering Miramichi rivers, New Brunswick, Canada. Geomorphology 69, 253-274.

Burge, L.M. (2006) Stability, morphology and surface grain-size patterns of channel bifurcation in gravel-cobble bedded anabranching rivers. Earth Surface Processes and Landforms 31, 1211-1226.

Burge, L.M. and Lapointe, M.F. (2005) Understanding the temporal dynamics of the wandering Renous River, New Brunswick, Canada. Earth Surface Processes and Landforms, 30, 1227-1250.

Church, M. (1983) Pattern of instability in a wandering gravel bed channel. In: Modern and Ancient Fluvial Systems (Eds J.D. Collinson and J. Lewin), pp. 169-180. Blackwell Scientific, Oxford, UK.

Church, M., Ham, D. and Weatherly, H. (2001) Gravel management in lower Fraser River. Report to the City of Chilliwack. Department of Geography, UBC, Vancouver, Canada, $104 \mathrm{pp}$.

Church, M. and Jones, D. (1982) Channel bars in gravel-bed rivers. In: Gravel-bed rivers (Eds R.D. Hey, J.C. Bathurst and C.R. Thorne), pp. 291-338. John Wiley and Sons, Chichester.

Collinson, J.D. (1970) Bedforms of the Tana River, Norway. Geografiska Annaler, 52A, 3156. 
Desloges, J.R. and Church, M. (1987) Channel and floodplain facies in a wandering gravelbed river. In: Recent Developments in Fluvial Sedimentology (Eds F.G. Ethridge, R.M. Flores and M.D. Harvey), pp. 99-109. Society of Economic Paleontologists and Mineralogists, Tulsa, USA.

Dinehart, R.L. (1992) Evolution of coarse gravel bed forms: field measurements at flood stage. Water Resources Research, 28, 2667-2689.

Ferguson, R.I. and Werrity, A. (1983) Bar development and channel changes in the gravelly River Feshie, Scotland. In: Modern and Ancient Fluvial Systems (Eds J.D. Collinson and J. Lewin), pp. 181-193. Blackwell Science, Oxford, UK.

Ferguson, R.I., Prestegaard, K.L., Ashmore, P.E., Ashworth, P.J. and Paola, C. (1992) Measurements in a braided river chute and lobe. 1. Flow pattern, sediment transport, and channel change. Water Resources Research, 28, 1877-1886.

Forbes, D.L. (1983) Morphology and sedimentology of a sinuous gravel-bed channel system: lower Babbage River, Yukon coastal plain, Canada. In: Modern and Ancient Fluvial Systems (Eds J.D. Collinson and J. Lewin), pp. 195-206. Blackwell Scientific, Oxford, UK.

Fuller, I.C., Large, A.R.G. and Milan, D.J. (2003) Quantifying channel development and sediment transfer following chute cutoff in a wandering gravel-bed river. Geomorphology, 54, 307-323.

Germanoski, D. (2001) Bar forming processes in gravel-bed rivers, with implications for small-scale gravel mining. In: Applying geomorphology to environmental management (Eds D.J. Anthony, M.D. Harvey, J.B. Laronne and M.P. Mosley), pp. 3-323. Water Resources Publications, Highlands Ranch, Colorado, USA.

Gustavson, T.C. (1978) Bed forms and stratification types of modern gravel meander lobes, Nueces River, Texas. Sedimentology, 25, 401-426.

Ham, D.G. (2005) Morphodynamics and sediment transport in a wandering gravel-bed channel: Fraser River, British Columbia. Unpublished PhD Thesis. University of British Columbia, Canada.

Hein, F.J. and Walker, R.G. (1977) Bar evolution and development of stratification in the gravelly, braided, Kicking Horse River, British Columbia. Canadian Journal of Earth Science, 14, 562-570.

Kelly, S. (2006) Scaling and hierarchy in braided rivers and their deposits: examples and implications for reservoir modelling. In: Braided Rivers: Process, Deposits, Ecology and Management (Eds G.H. Sambrook Smith, J.L. Best, C.S. Bristow and G.E. Petts) pp 75106. IAS Special Publication 36.

Jackson, R.G. II (1975) Hierarchical attributes and a unifying model of bedforms composed of cohesionless material and produced by shearing flow. Geological Society of America Bulletin, 86: 1523-1533.

Jackson, R.G. II (1978) Preliminary evaluation of lithofacies models for meandering alluvial streams. In: Fluvial Sedimentology (Ed A.D. Miall), pp. 543-576. Canadian Society of Petroleum Geologists, Calgary, Alberta, Canada.

Krigström, A. (1962) Geomorphological studies of sandur plains and their braided rivers in Iceland. Geografiska Annaler 44, 328-346.

Lane, S.N. (2001) The measurement of gravel-bed river morphology. In: Gravel-bed Rivers V (Ed. M.P. Mosley), 291-397. New Zealand Hydrological Society, Wellington.

Leclerc, R. and Hickin, E.J. (1997) Ground penetrating radar stratigraphy of a meandering river floodplain, South Thompson River, British Columbia. Geomorphology, 21, 17-38.

Lewin, J. (1976) Initiation of bed forms and meanders in coarse-grained sediment. Geological Society of America Bulletin, 87, 281-285. 
Livesey, J.R., Bennett, S., Ashworth, P.J. and Best, B.J. (1998) Flow structure, sediment transport and bedform dynamics for a bimodal sediment mixture. In: Gravel-Bed Rivers in the Environment (Eds P.C. Klingeman, R.L. Beschta, P.D. Komar and J.B. Bradley), pp. 149-176. Water Resources Publications, Highlands Ranch, Colorado, USA.

Lunt, I.A., Bridge, J.S. and Tye, R.S. (2004) A quantitative, three-dimensional depositional model of gravelly braided rivers. Sedimentology, 51, 377-414.

Martini, I.P. (1977) Gravelly flood deposits of Irvine Creek, Ontario, Canada. Sedimentology, 24, 603-622.

McCullagh, M.J. (1998) Quality, use and visualisation in terrain modelling. In: Landform Monitoring, Modelling and Analysis (Eds S.N. Lane, K.S. Richards and J.H. Chandler), pp. 95-117. John Wiley and Sons, Chichester.

McLean, D.G. and Church, M. (1999) Sediment transport along lower Fraser River: 2. Estimates based on the long-term gravel budget. Water Resources Research, 35, 25492559.

McLean, D.G., Church, M. and Tassone, B. (1999) Sediment transport along lower Fraser River: 1. Measurements and hydraulic computations. Water Resources Research, 35, 2533-2548.

Miall, A.D. (1977) A review of the braided river depositional environment. Earth Science Reviews, 13: 1-62.

Miall, A.D. (2000) Principles of Sedimentary Basin Analysis (third Edition). Springer-Verlag, Berlin, 616 pp.

North, M.E.A. and Teversham, J.M. (1984) The vegetation of the floodplains of the lower Fraser, Serpentine and Nicomekl rivers, 1859 to 1890. Syesis, 17, 47-66.

Paola C. and Foufoula-Georgiou, E. (2001) Statistical geometry and dynamics of braided rivers. In: Gravel-Bed Rivers V (Ed. Mosley, P.), pp 47-71. New Zealand Hydrological Society, Wellington.

Passmore, D.G. and Macklin, M.G. (2000) Late Holocene channel and floodplain development in a wandering gravel-bed river: The River South Tyne at Lambley, Northern England. Earth Surface Processes and Landforms, 25, 1237-1256.

Prestegaard, K.L. (1987) Sediment transport and deposition zones in braided streams. In: Erosion and Sedimentation in the Pacific Rim (Eds R.L. Beschta, T. Blinn, G.E. Grant, F.J. Swanson and G.G. Ice), pp. 411-412. International Association of Hydrological Sciences Press, Wallingford, UK.

Rice, S.P. and Church, M. (1998) "Grain size along two gravel-bed rivers: statistical variation, spatial pattern and sedimentary links", Earth Surface Processes and Landforms, 23, 345363.

Roberts, M.C., Bravard, J. and Jol, H.M. (1997) Radar signatures and structure of an avulsed channel: Rhone River, Aoste, France. Journal of Quaternary Science, 12, 35-42.

Ruse, B.R. and Koster, E.H. (1984) Coarse alluvial deposits. In: Facies Models (Ed R.G. Walker), pp. 53-69. Geoscience Canada, Reprint Series 1 (second edition).

Smith, N.D. (1974) Sedimentology and bar formation in the Upper Kicking Horse River, a braided outwash stream. Journal of Geology, 82, 205-223.

Smith, N. (1978) Some comments on terminology for bars in shallow rivers. In: Fluvial Sedimentology (Ed A.D. Miall), pp. 85-88. Canadian Society of Petroleum Geologists, Calgary, Alberta, Canada.

Southard, J.B., Smith, N.D. and Kuhnle, R.A. (1984) Chutes and lobes: newly identified elements of braiding in shallow gravelly streams. In: Sedimentology of gravels and conglomerates (Eds E.H. Koster and R.J. Steel), pp. 51-59. Canadian Society of Petroleum Geologists, Calgary, Alberta, Canada 
Whiting, P.J., Dietrich, W.E., Leopold, L.B., Drake, T.G. and Shreve, R.L. (1988) Bedload sheets in heterogeneous sediment. Geology, 16, 105-108.

Williams P.F. and Rust B.R. (1969) The sedimentology of a braided river. Journal of Sedimentary Petrology, 39, 649-679.

Wooldridge, C.L. and Hickin, E.J. (2005) Radar architecture and evolution of channel bars in wandering gravel-bed rivers: Fraser and Squamish Rivers, British Columbia, Canada. Journal of Sedimentary Research, 75, 842-858. 
Table 1. Cut and fill on parts of Queens and Calamity Bars during two recent freshets.

\begin{tabular}{|c|c|c|c|}
\hline & $\begin{array}{c}\text { Queens } \\
\text { Sept. } 2000-\text { April } \\
2000\end{array}$ & $\begin{array}{c}\text { Queens } \\
\text { Dec. } 2003 \text { - March } \\
2002\end{array}$ & $\begin{array}{c}\text { Calamity } \\
\text { April } 2003 \text { - March } \\
2002\end{array}$ \\
\hline \multicolumn{4}{|l|}{ Plan areas $\left(\mathrm{m}^{2}\right)$} \\
\hline no change & $101163(30 \%)$ & $39278(11 \%)$ & $58809(31 \%)$ \\
\hline net fill & $134125(40 \%)$ & $208717(60 \%)$ & $101266(54 \%)$ \\
\hline net cut & $102483(30 \%)$ & $101876(29 \%)$ & $29183(15 \%)$ \\
\hline \multicolumn{4}{|l|}{ Volumes $\left(\mathbf{m}^{3}\right)$} \\
\hline total net fill & 43589 & 142463 & 30631 \\
\hline total net cut & -30529 & -82267 & -6160 \\
\hline total net change & 13060 & 60196 & 24471 \\
\hline \multicolumn{4}{|l|}{ Mean depth (m) } \\
\hline Fill & 0.33 & 0.68 & 0.30 \\
\hline Cut & -0.30 & -0.81 & -0.21 \\
\hline \multicolumn{4}{|l|}{$\begin{array}{l}95^{\text {th }} \text { percentile } \\
\text { (m) }\end{array}$} \\
\hline Fill & 1.27 & 1.93 & 1.12 \\
\hline Cut & -1.05 & -1.95 & -0.78 \\
\hline
\end{tabular}

Values are for cut (net erosion) and fill (net deposition) in excess of the minimum detectable difference $\left( \pm 2 \mathrm{D}_{50}\right): \pm 0.055 \mathrm{~m}$ on Queens and $\pm 0.061 \mathrm{~m}$ on Calamity. Values refer to the areas mapped in Figures 10 and 11. 
Table 2. Long-term bed material budget for Queens and Calamity Bars

\begin{tabular}{lrrr}
\hline \multicolumn{1}{c}{$\Delta V$} & \multicolumn{1}{c}{$\Delta V / \mathrm{a}$} & \multicolumn{1}{c}{$\Delta V / \mathrm{km} . \mathrm{a}$} \\
\hline Queens Bar (1952-2003) & & \\
Bar only & $1148822 \pm 79348$ & $22526 \pm 1556$ & $6088 \pm 421$ \\
Bar + channel & $-89438 \pm 162080$ & $-1754 \pm 3178$ & $-474 \pm 859$ \\
& & & \\
Calamity Bar & & & $11318 \pm 205$ \\
Bar only & $750353 \pm 13545$ & $14713 \pm 266$ & $3487 \pm 643$ \\
Bar + channel & $231176 \pm 42613$ & $4533 \pm 836$ & \\
& & & \\
\hline
\end{tabular}

Queens Bar (1999-2003)

$\begin{array}{lccc}\text { Bar only } & -813982 \pm 23989 & -203496 \pm 5997 & -54999 \pm 1621 \\ \text { Bar + channel } & -858962 \pm 49001 & -214741 \pm 1225 & -58038 \pm 331 \\ & & & \\ \text { Calamity Bar } & -3481 \pm 410 & -870 \pm 103 & -669 \pm 515 \\ \text { Bar only } & 212992 \pm 12883 & 53245 \pm 3221 & 40960 \pm 2478 \\ \text { Bar + channel } & & & \end{array}$

All data are $\mathrm{m}^{3}$ bulk measure, computed from topographic differences between surveys conducted by bathymetry and terrestrial surveying or airborne Lidar. Underlying RMS elevation differences between surveys are estimated to be $\pm 4.3 \mathrm{~cm}$ for the period 1952-2003 and $\pm 1.3 \mathrm{~cm}$ for the period 1999-2003 (from data reported in Ham, 2005), with the possibility for an underlying bias of about $5 \mathrm{~mm}$ (i.e., one order of magnitude smaller than the precision). Errors of bar and channel areas are not considered as they will be comparatively very small. The estimates per kilometre are based on the length of Queens Bar being $3.7 \mathrm{~km}$, and of Calamity Bar being $1.3 \mathrm{~km}$.

Table 3. Calamity Bar accretion rates determined from bathymetric data

\begin{tabular}{lccc}
\hline $\begin{array}{c}\text { Bathymetric } \\
\text { Differencing }\end{array}$ & $\begin{array}{c}\text { Vertical aggradation } \\
\left(\mathrm{m} \mathrm{a}^{-1}\right)\end{array}$ & $\begin{array}{c}\text { Lateral accretion } \\
\left(\mathrm{m} \mathrm{a}^{-1}\right)\end{array}$ \\
\hline $1952-1984$ & 0.10 & & 1.56 \\
$1984-1999$ & 0.15 & 3.67 \\
$1952-1999$ & & 0.12 & \multicolumn{2}{c}{2.23} \\
\hline
\end{tabular}


Figure 1. Fraser River gravel reach between Laidlaw and Mission, British Columbia, Canada. River kilometres are measured from Sand Heads (mouth of the river); the major bars are named.

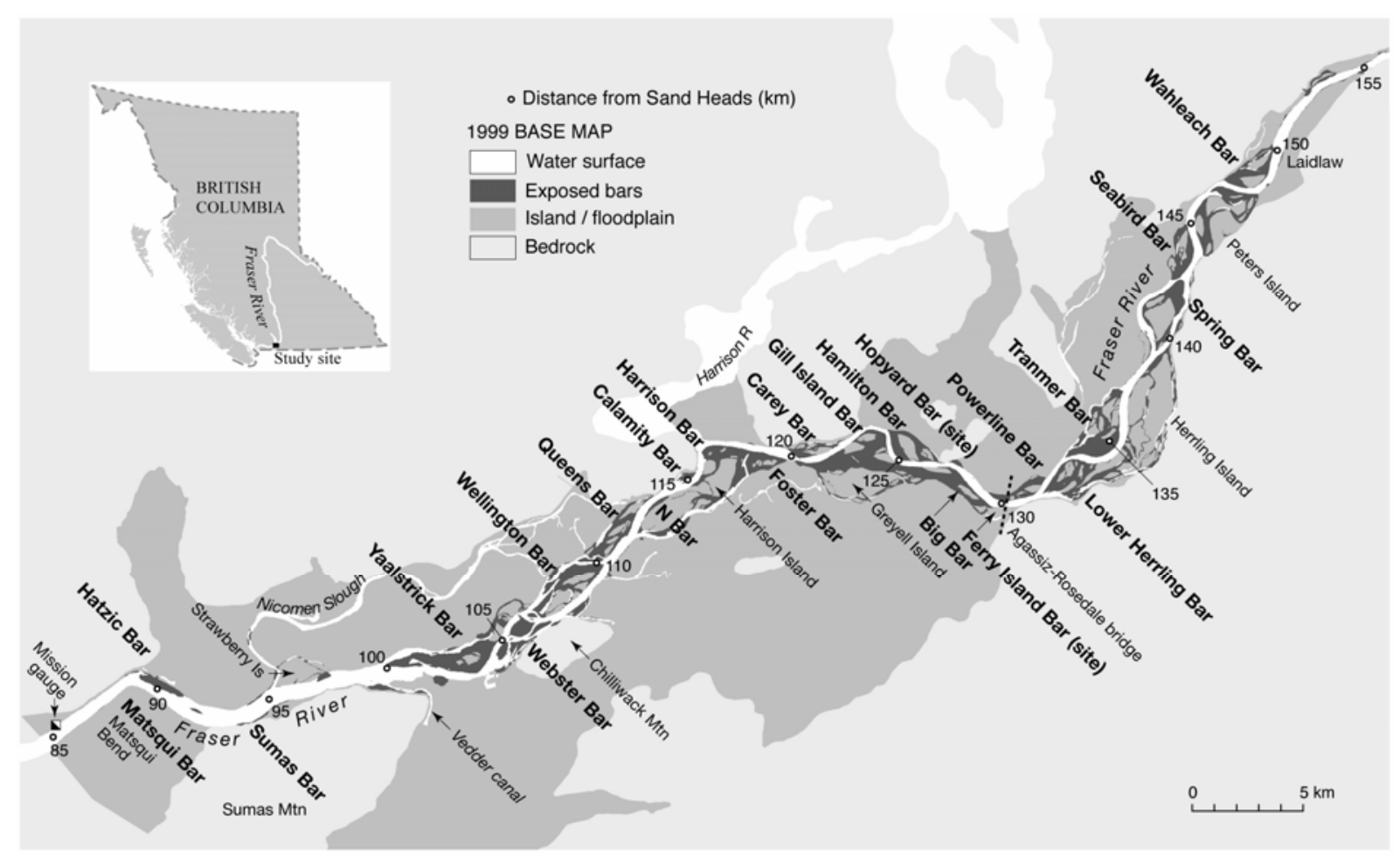


Figure 2. Location of Queens and Calamity Bars and the layout of the topographic surveys. In the photograph, taken in March 2000 at a discharge of approximately $700 \mathrm{~m}^{3} \mathrm{~s}^{-}$ ${ }^{1}$, flow is from top to bottom (photo ID: SRS 6164 79-82). Data points are shown for the April 2000 surveys.
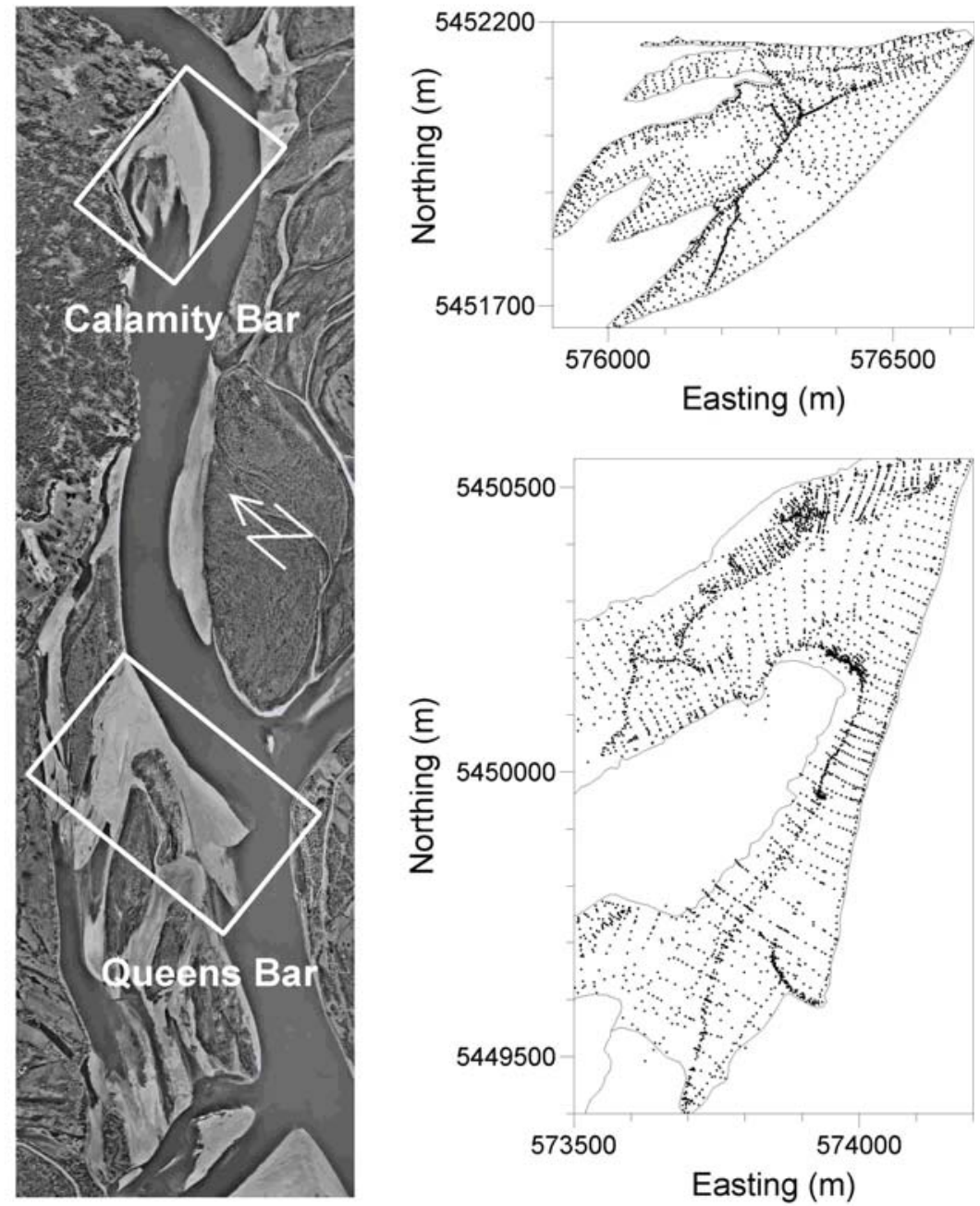
Figure 3. Sedimentation patterns in the Chilliwack reach of the river. Compound bars (A) are located within the familiar pattern of pool-riffle-bar triplets (B and C).

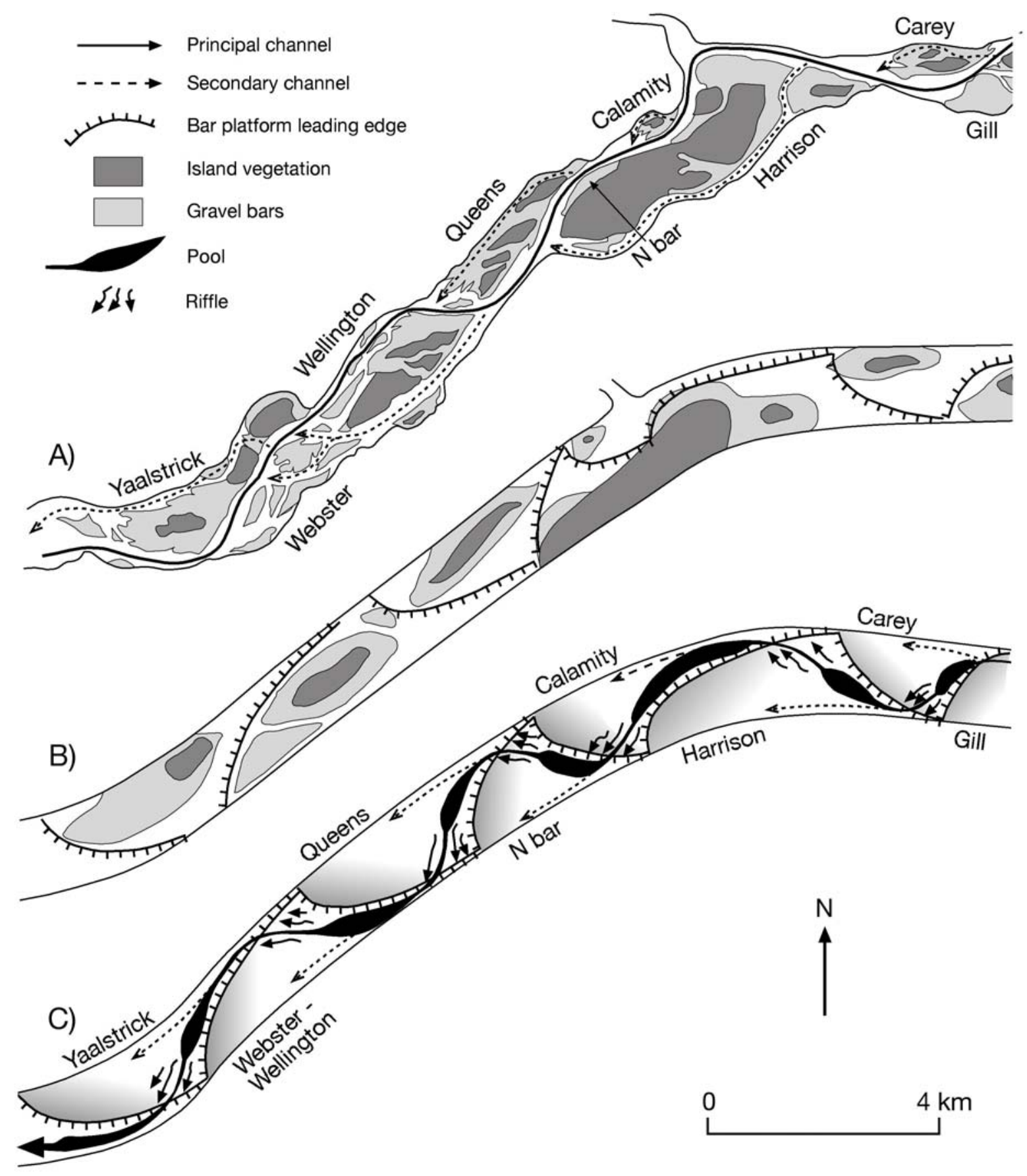


Figure 4. Examples of compound bar types in the Fraser River gravel reach: (A) elongated and (B) compact laterally attached bars; (C) medial bar. Queens, Hamilton and Spring Bars respectively.
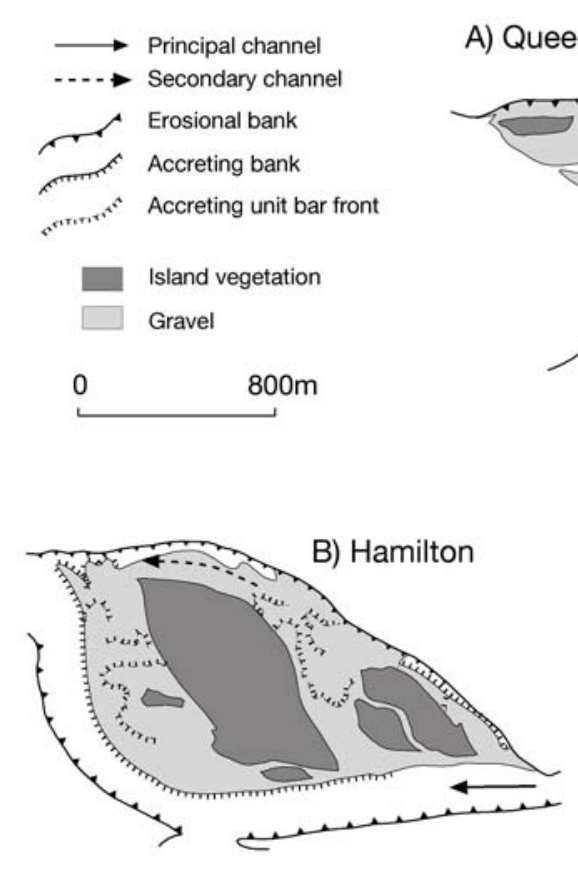
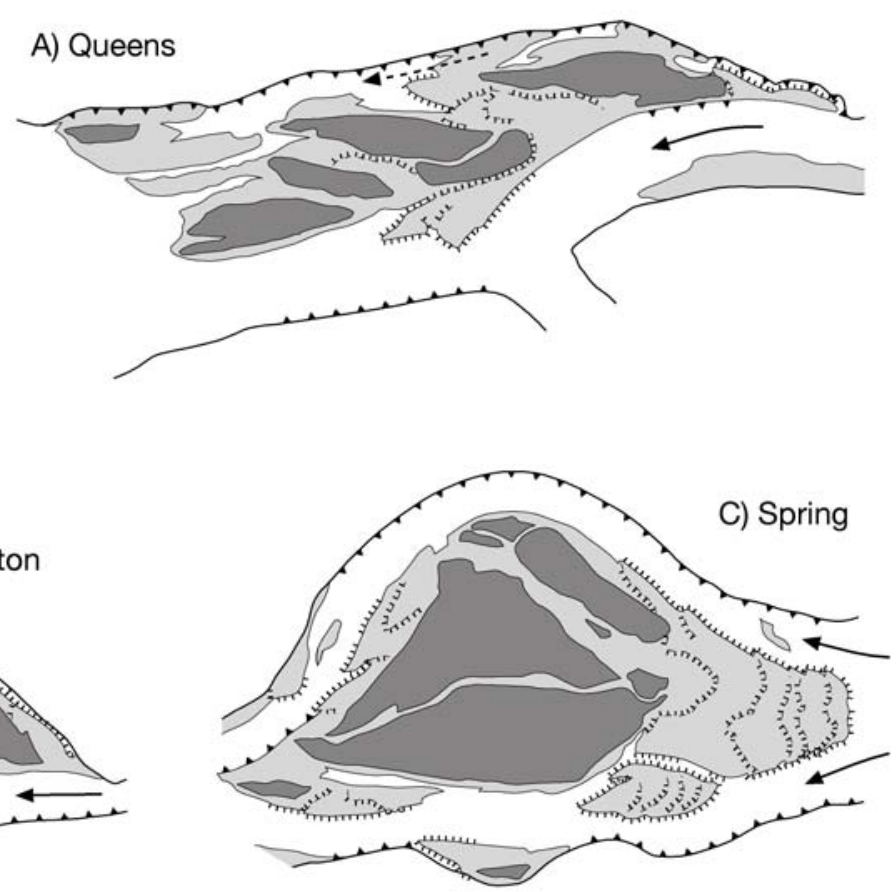
Figure 5. Examples of gravel sheets and unit bars. Migrating bedload sheets with distinct topographic and sedimentological boundaries (A and B) contrast with sheet edges that are more diffuse $(C)$. Unit bar avalanche faces may be a few tens of centimetres to several metres high $(\mathrm{D}, \mathrm{E})$ and are backed by extensive horizontal or low angle stoss-side platforms (F). Note the partially buried willow trees emerging through the advancing unit in $\mathrm{E}$. The orientation and location of photographs $\mathrm{E}$ and $\mathrm{F}$ are indicated on Figure 7A. In (A) the darker sheet advancing from left to right has a leading edge approximately $0.15 \mathrm{~m}$ high. In (B) the tape is stretched out to $0.5 \mathrm{~m}$. In (C) the pencil is approximately $0.15 \mathrm{~m}$ long. The slip face in panels (D), (E) and (F) are approximately $0.4,1.0$ and $1.5 \mathrm{~m}$ high, respectively.
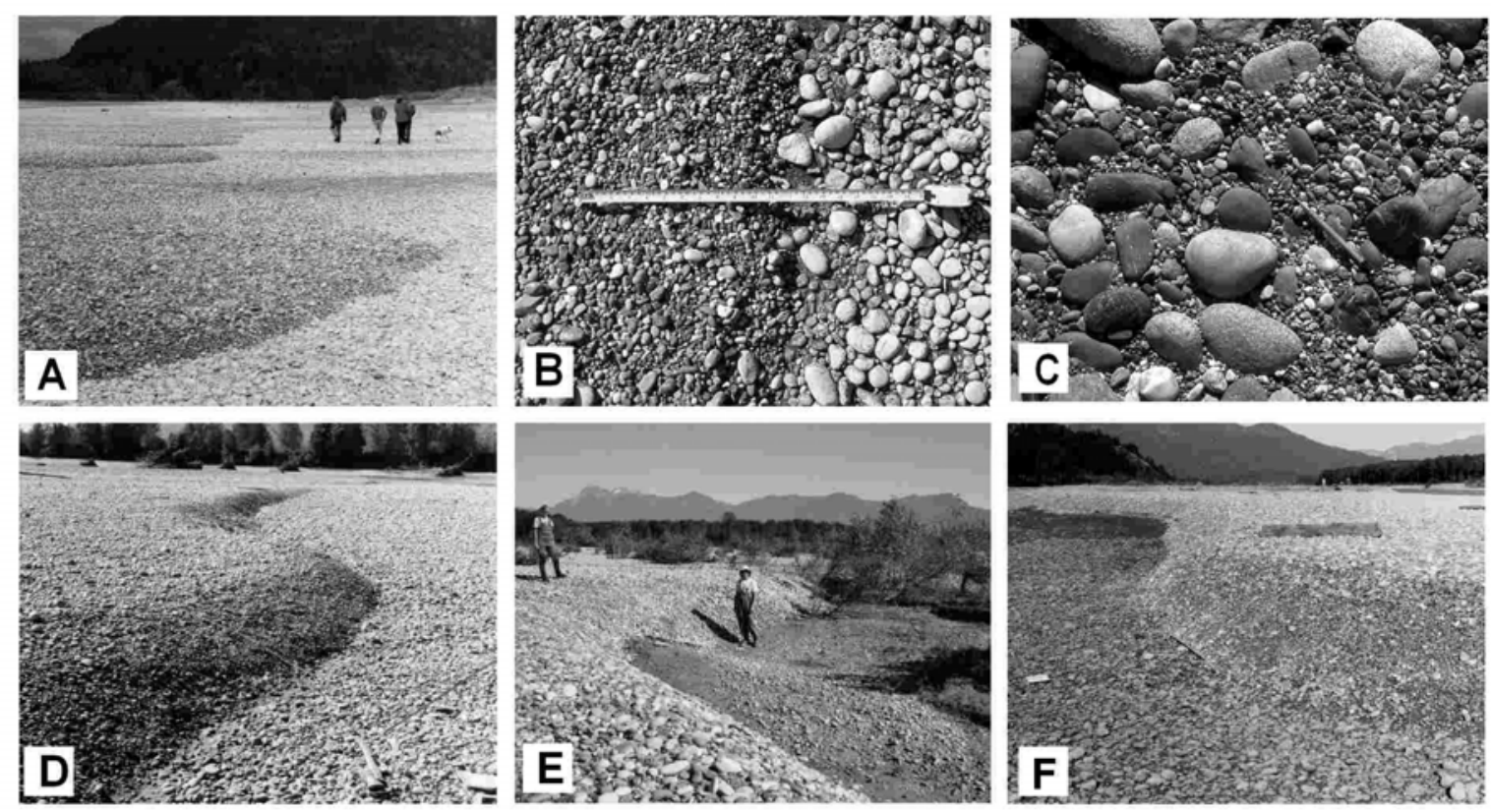
Figure 6. Styles of primary unit bar accretion. Flank unit bars on (A) Carey and (B) Tranmer Bars with elongate and crescentic morphologies respectively. Bar-head units on (C) Spring and (D) Hamilton Bars producing chevron morphology. Arrows indicate flow direction. In panels (A), (B) and (D) the wetted channel is approximately 600, 400 and $300 \mathrm{~m}$ wide respectively. In panel (C) the central portion of the bar head is approximately $600 \mathrm{~m}$ wide.
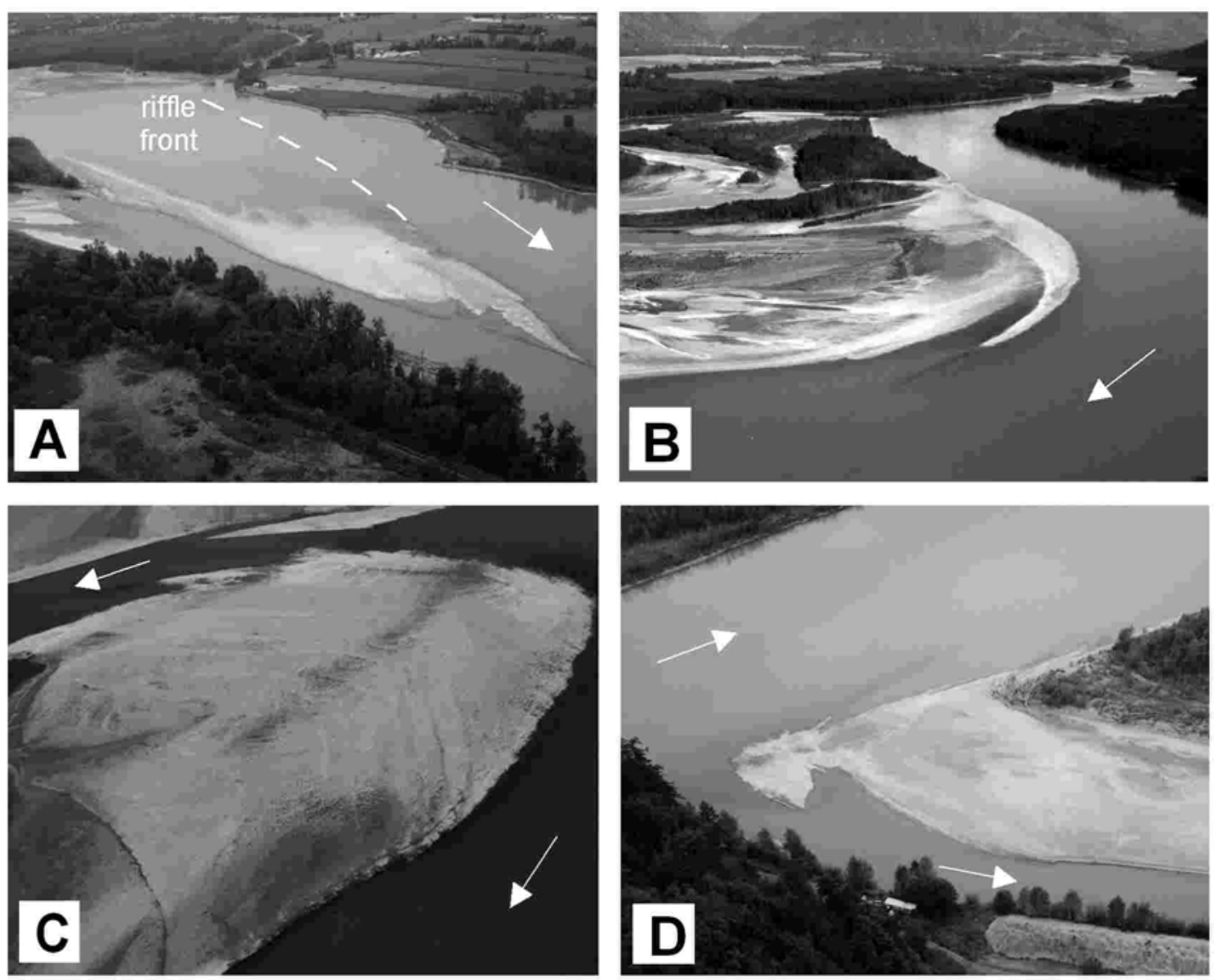
Figure 7. Features of supra-platform morphology with examples from (A) Queens and (B) Calamity Bars: (1) elongate and (2) compact flank unit bar accretion; (3) primary bar-head unit bar accretion (see also Figure 5E); (4) simple reworking in a secondary channel to produce a mouth bar; (5) lateral erosion of a stalled transverse unit bar in the seasonal anabranch; (6) headward erosion of bar-top channels; (7) complex stacking of transverse secondary unit bars; (8) confined, lobate, longitudinal bar in a bar-top channel; and (9) a mouth bar generated by dissection of transverse unit bars. The orientation and location of photographs $\mathrm{E}$ and $\mathrm{F}$ in Figure 5 are indicated. Maps and cross-sections appear with five times vertical exaggeration.
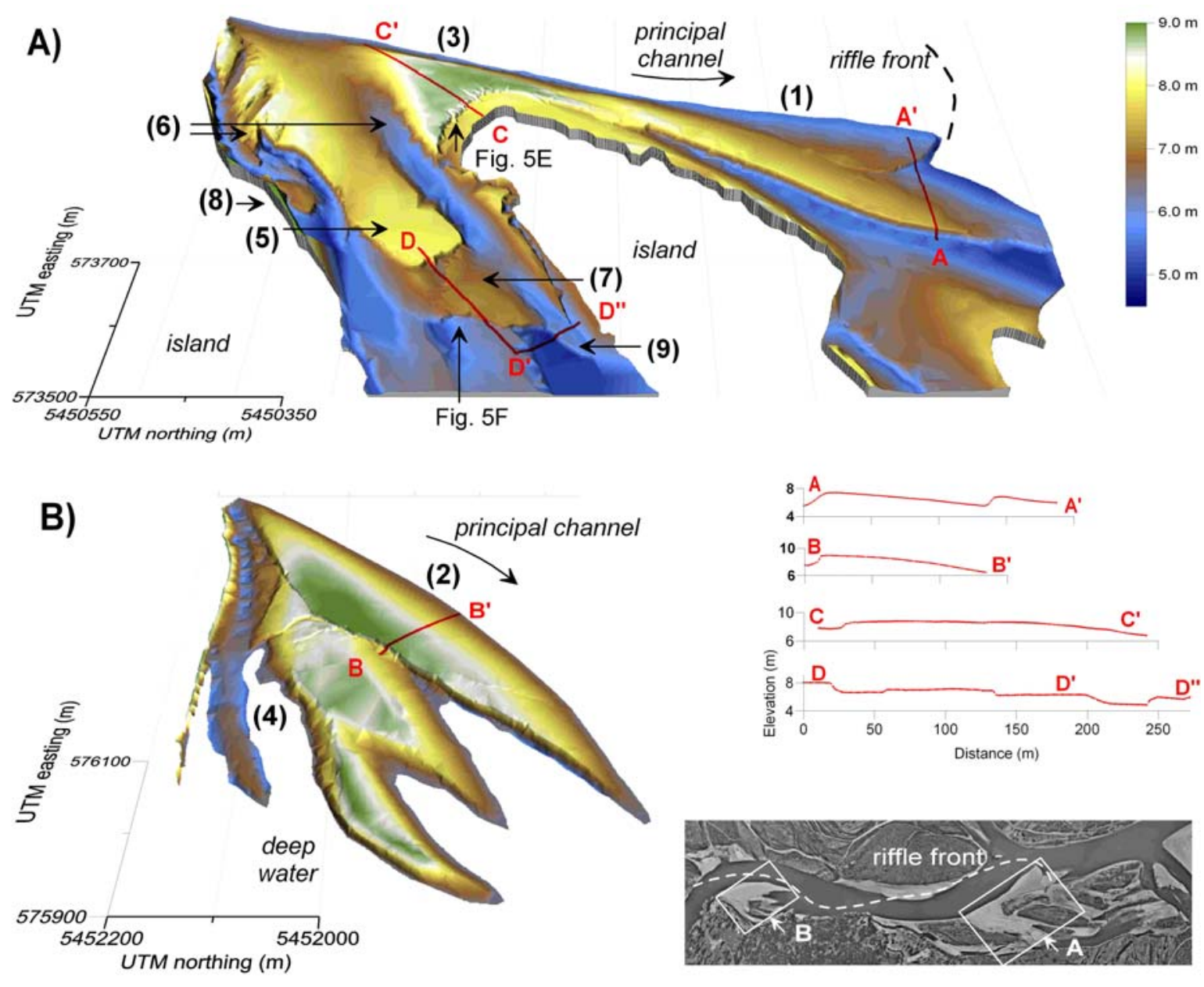
Figure 8. Slip-face grooves and lobes: (A) forming at falling stage on Hamilton Bar (A4 notepad for scale); (B) exposed linear tongue with arcuate slip-face and horizontal upper surface (the height of the person is $1.8 \mathrm{~m}$ ).
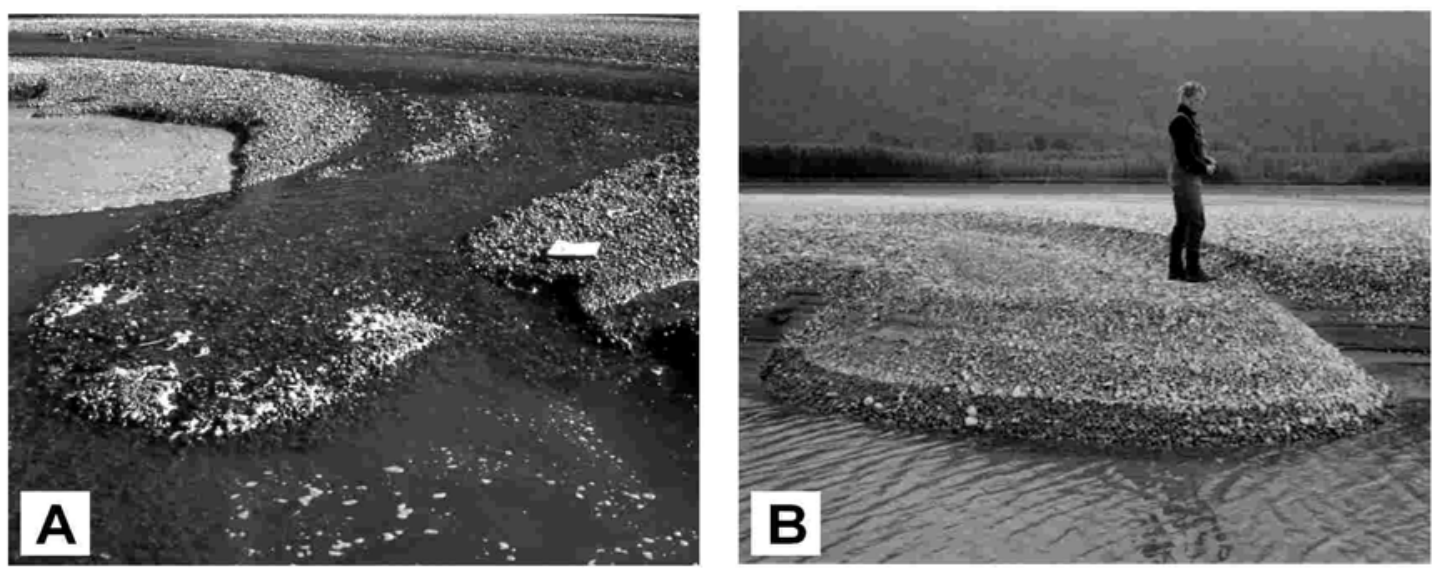
Figure 9. Hierarchical typology of channels and bars in the wandering lower Fraser River. See text for details. Values in parentheses are multiples of the principal channel width.

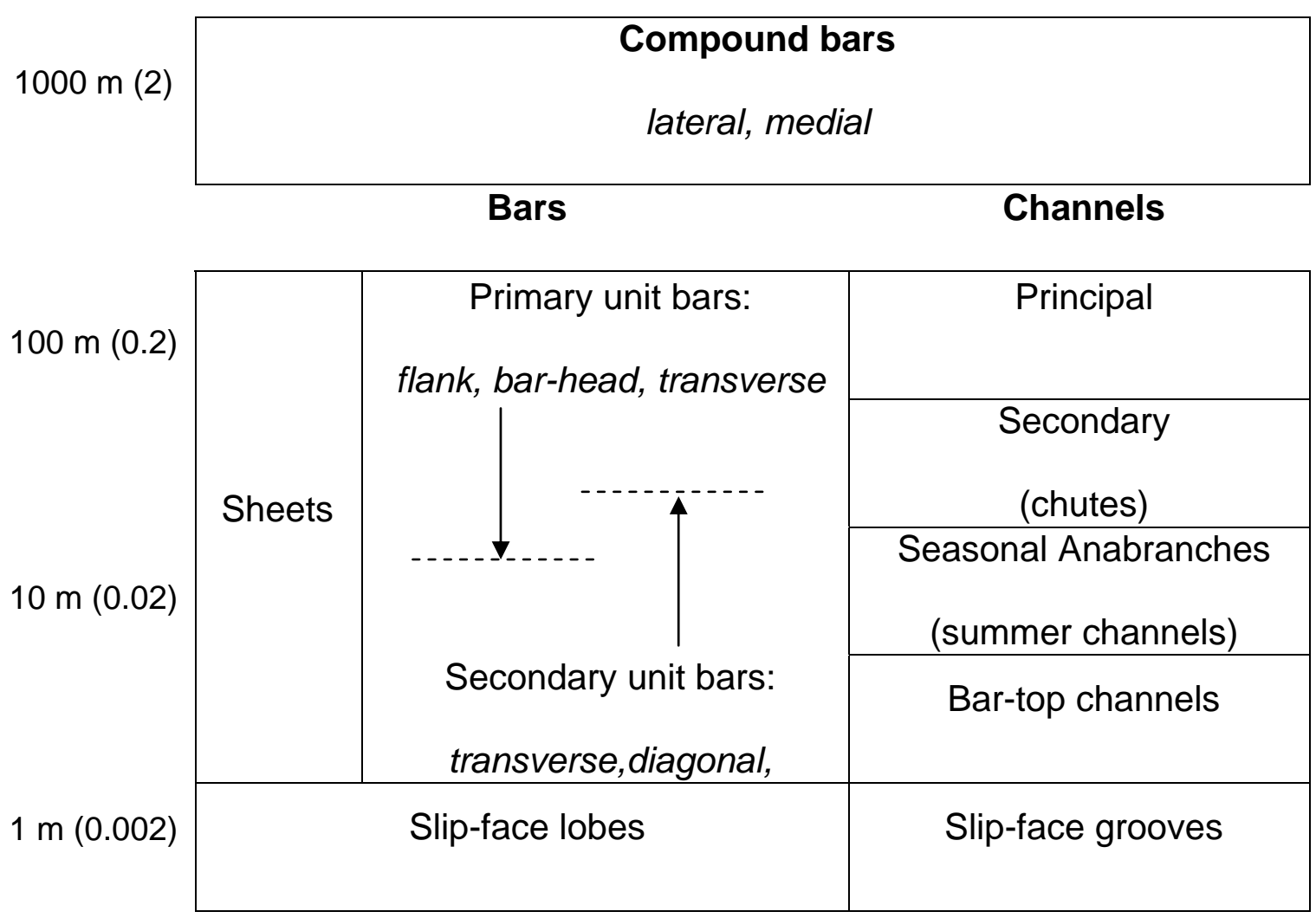


Figure 10. Morphological change on Queens Bar caused by (A) the 2000 freshet and (B) the 2002 freshet. Scale bar units are $\mathrm{m}$. Each panel shows the topography before and after the freshet (surveys April and September 2000, March 2002 and December 2003 ) and the DEM of difference for the common survey area (older surface minus younger surface in each case). White areas (also indicated by the box on the colour scale) indicate elevation changes that are less than the minimum detectable difference $\left( \pm 2 \mathrm{D}_{50}= \pm 0.055 \mathrm{~m}\right)$. Dashed lines show the limits of the older surveys and the solid lines the limit of the younger surveys. Annotations are based on field observations. Numbers refer to comments made in the text and the dotted line demarcates the approximate boundaries of the transverse unit bar (6) for which specific cut and fill calculations are presented in the Discussion.
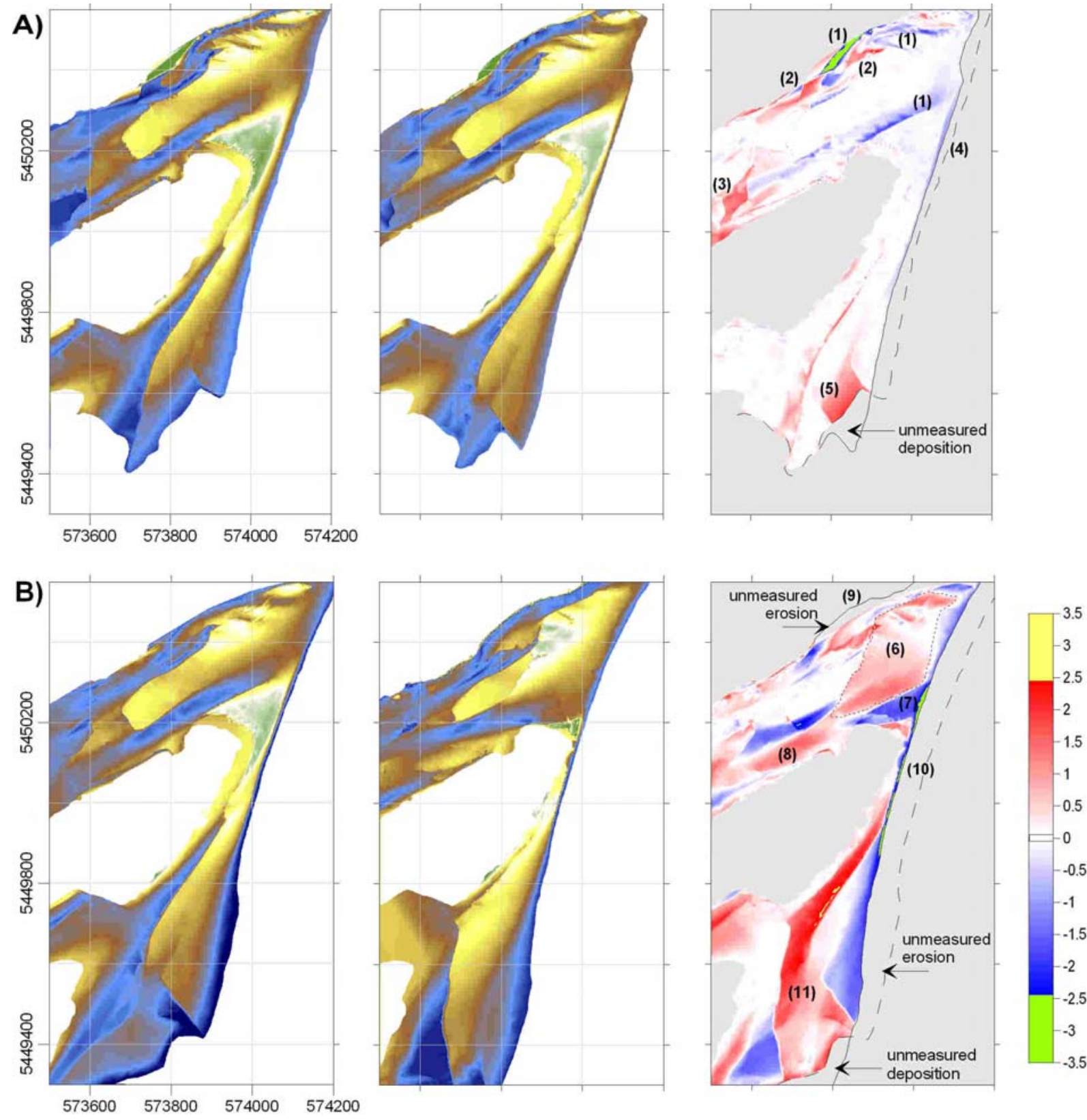
Figure 11. Morphological change on Calamity Bar caused by the 2002 freshet, showing topography before and after the freshet (surveys March 2002 and April 2003) and the DEM of difference for the common survey area (older surface minus younger surface). Scale bar units are $\mathrm{m}$. White areas (also indicated by the box on the colour scale) indicate elevation changes that are less than the minimum detectable difference $\left( \pm 2 \mathrm{D}_{50}= \pm 0.061 \mathrm{~m}\right)$. The dashed line shows the survey limit of the older survey and the solid line the limit of the younger survey. Annotations are based on field observations and the dotted line demarcates the approximate boundaries of the flank unit bar (1) for which specific cut and fill calculations are presented. The bar thickens toward the limit of surveying close to the water's edge but presumably thins channel-ward beyond the limit of the survey. As explained in the methodology, surveys were limited to water depths that could be negotiated safely.
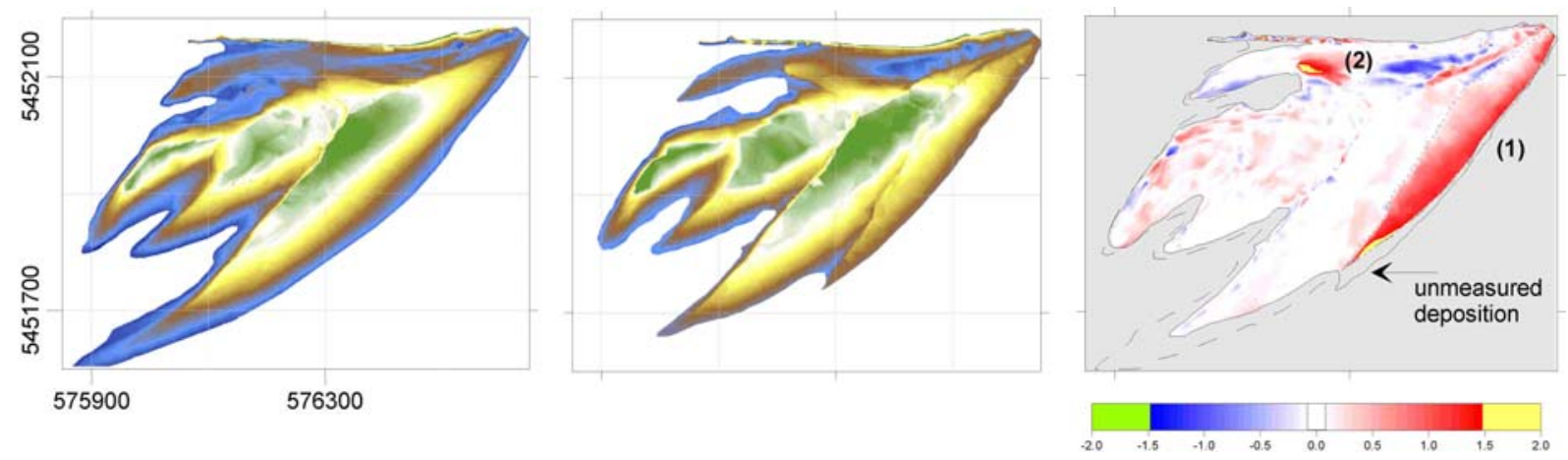
Figure 12. Sequential development of Calamity Bar, 1938 to 2003. The planimetric maps are constructed from vertical air photographs with full rectification. Photos were selected for low flow; no suitable low flow images are available between 1979 and 1999, a period during which flow exceeded $10000 \mathrm{~m}^{3} \mathrm{~s}^{-1}$ on three occasions. The selected map dates each follow a major flood. The March 7, 2001 panel shows the position of the GPR network on Calamity Bar (Figure 16) and the thicker line is the transect shown in Figure 15.

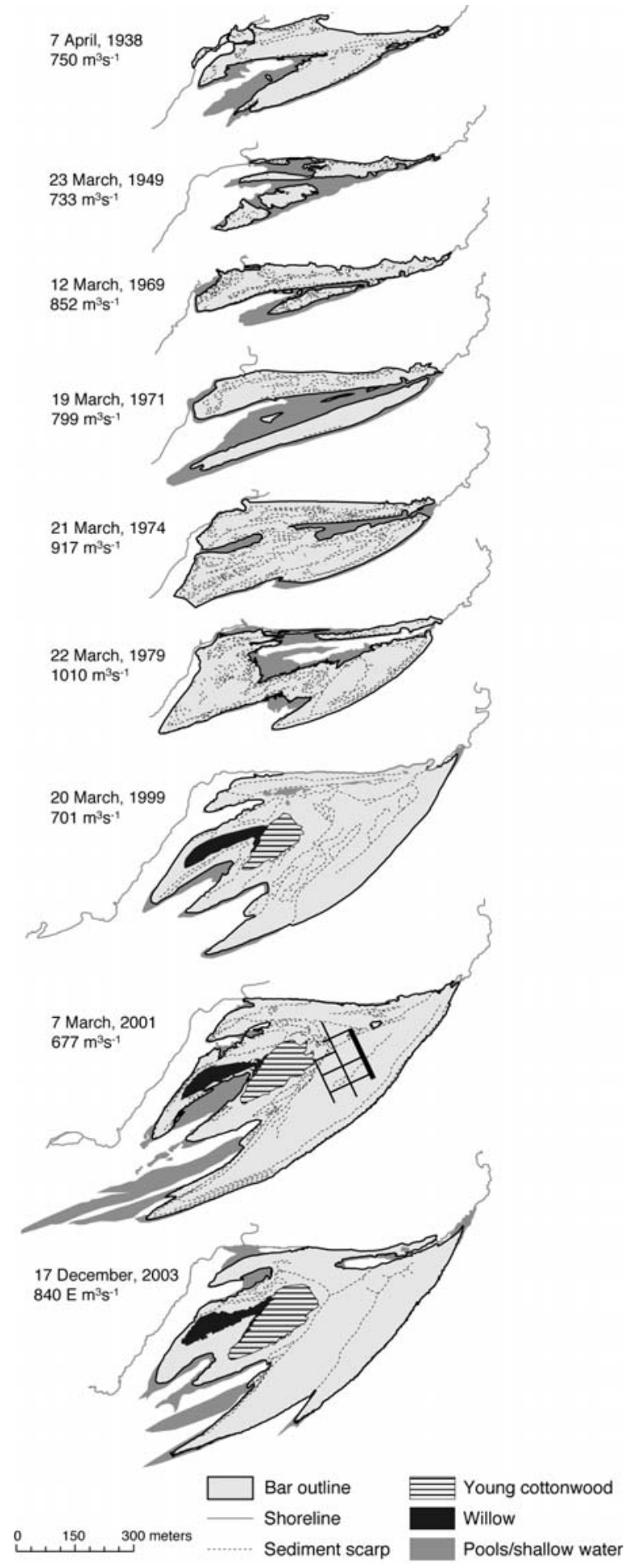


Figure 13. Air photo mosaics of Fraser River in the vicinity of Calamity Bar at four dates, showing the changes in river alignment that occurred during the middle years of the $20^{\text {th }}$ century and the consequent effect upon Calamity Bar. (A) 7 April, 1938, Hope flow, $\mathrm{Q}_{\mathrm{H}}=750 \mathrm{~m}^{3} \mathrm{~s}^{-1}$, photo A5869/4 (National Air Photo Library of Canada); Fraser River flows past Harrison Knob, a rockbound shore, and Calamity Bar forms on the inside bend. (B) 31 March, 1951, $\mathrm{Q}_{\mathrm{H}}=748 \mathrm{~m}^{3} \mathrm{~s}^{-1}$, photo S69-R1-149 (British Columbia Ministry of Lands and Forests); Fraser River has avulsed upstream and now enters directly from the east, while Harrison River discharges through the old channel. The growth of Calamity Bar is constrained. (C) $21 \mathrm{March}, 1974, \mathrm{Q}_{\mathrm{H}}=917 \mathrm{~m}^{3} \mathrm{~s}^{-1}$, photo BC5574/0215 (Province of British Columbia); the 1951 channel has silted up and flow is re-established in the 1938 channel. Calamity Bar commences its contemporary development. (D) 17 December, 2003, $\mathrm{Q}_{\mathrm{H}}=840 \mathrm{~m}^{3} \mathrm{~s}^{-1}$, photo SRS6906-124 (private flight); the contemporary bar. The grid of lines shown in panel D is the GPR grid shown in Figure 16 and the thicker line is the transect shown in Figure 15.
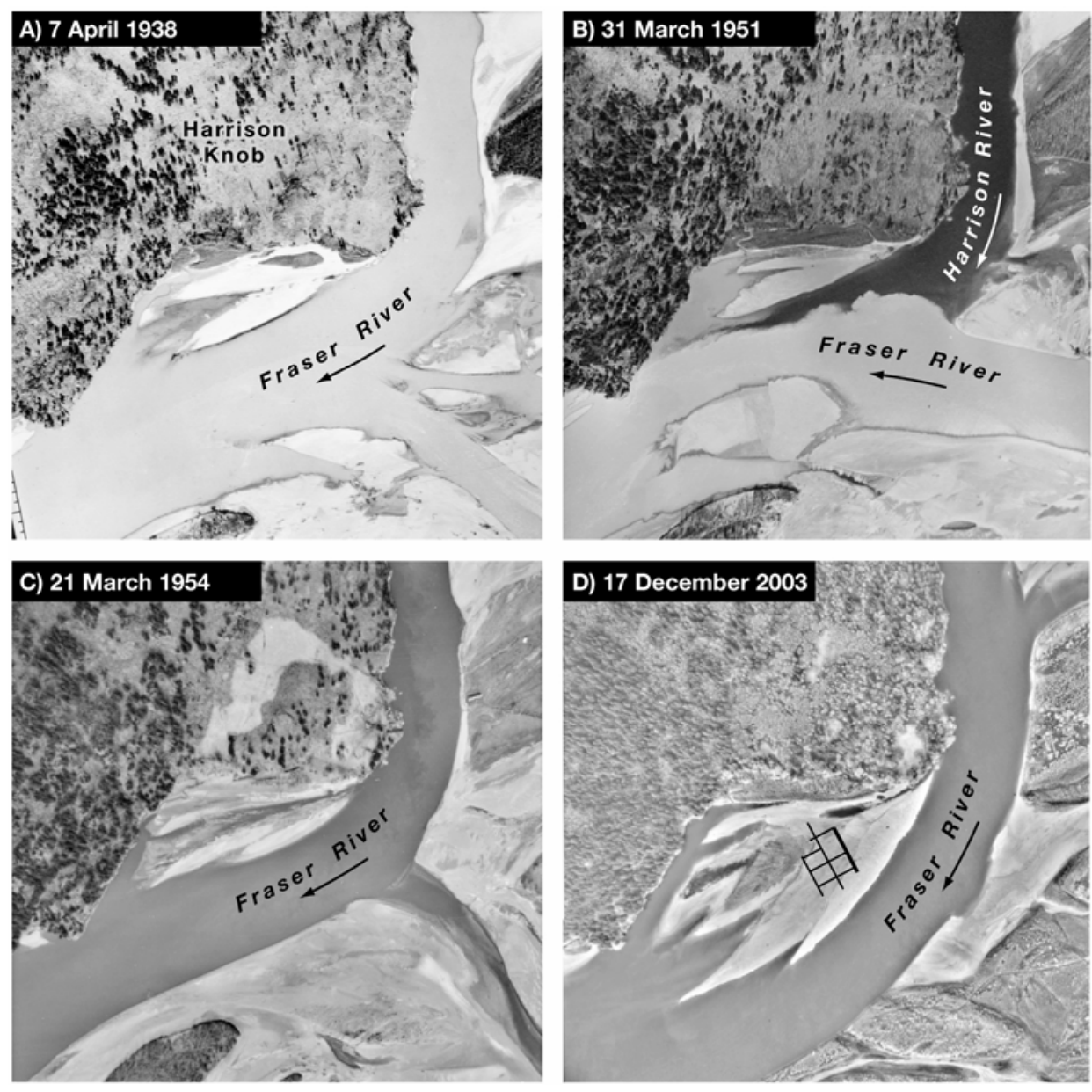
Figure 14. Sequential development of Queens Bar, 1938 to 2003. The planimetric maps are constructed from vertical air photographs with full rectification. Photos were selected for low flow. Between 1974 and 1999 Queens Bar remained essentially stable. After 1990, a left bank bar began to accumulate opposite upper Queens Bar, initiating erosion along the Queens Bar shore and the renewed lateral accretion mid-bar. The selected map dates each follow a major flood.

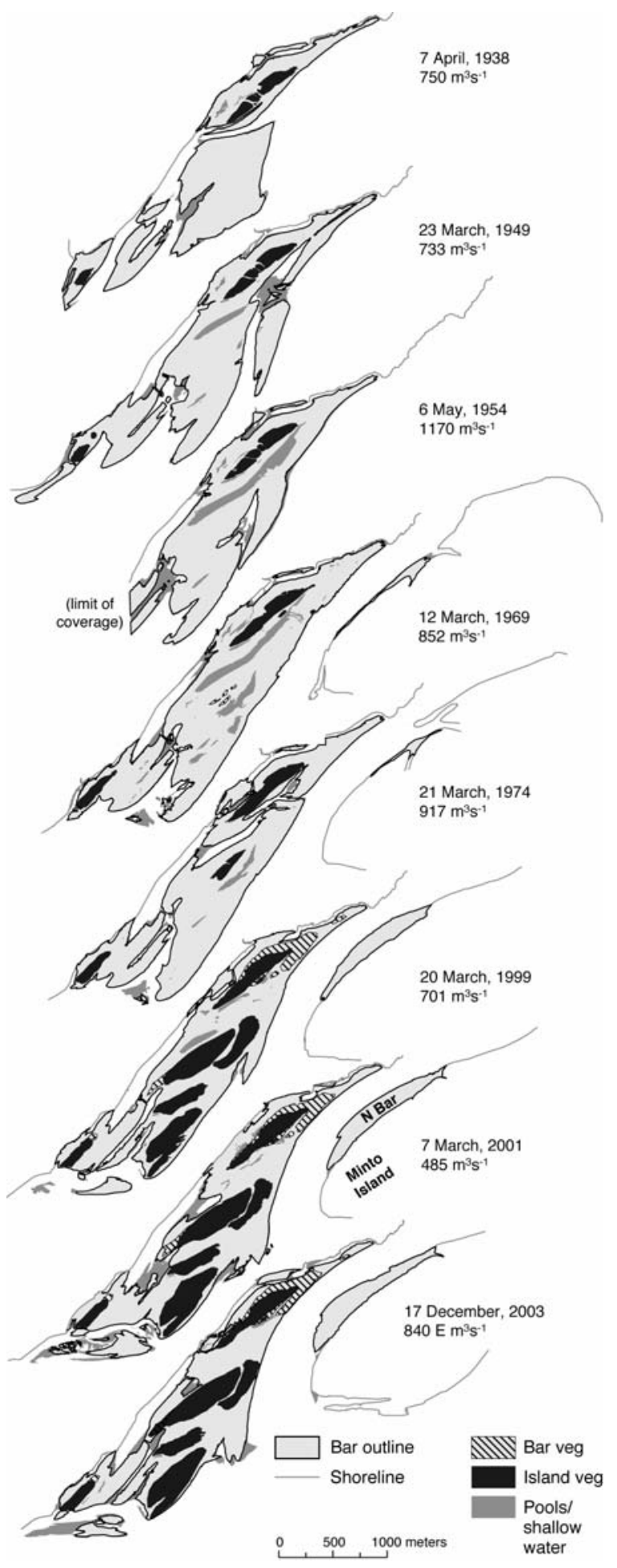


Figure 15. (A) $100 \mathrm{MHz}$ flow-normal GPR profile across Calamity Bar at mid-bar position; (B) interpreted profile with 1952 and 1984 bathymetric soundings superimposed. Vertical exaggeration of 1.5 times in each case. Circled numbers indicate distinctive radar facies and are consistent with the notation established in Wooldridge and Hickin (2005). Details of the interpretations are given in the text. See Figure 12 for the position of the profile line. The illustrated line is line b-d in Figure 16, the most upstream flow-normal face.

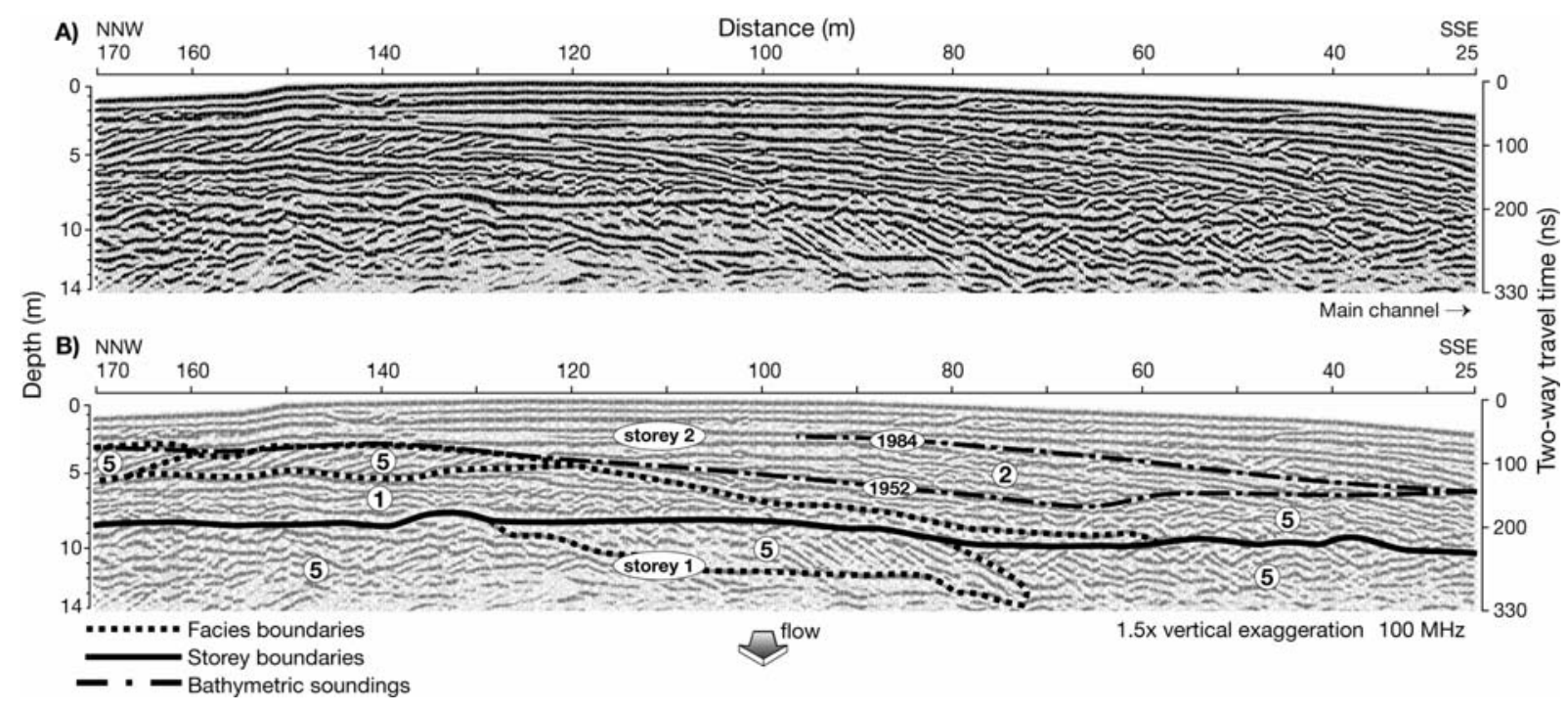


Figure 16. Fence diagram identifying the major radar facies of Calamity Bar, constructed from the complete network of radar soundings. See Figure 12 for the positions of the profile lines. Line bd is shown in original detail in Figure 15.

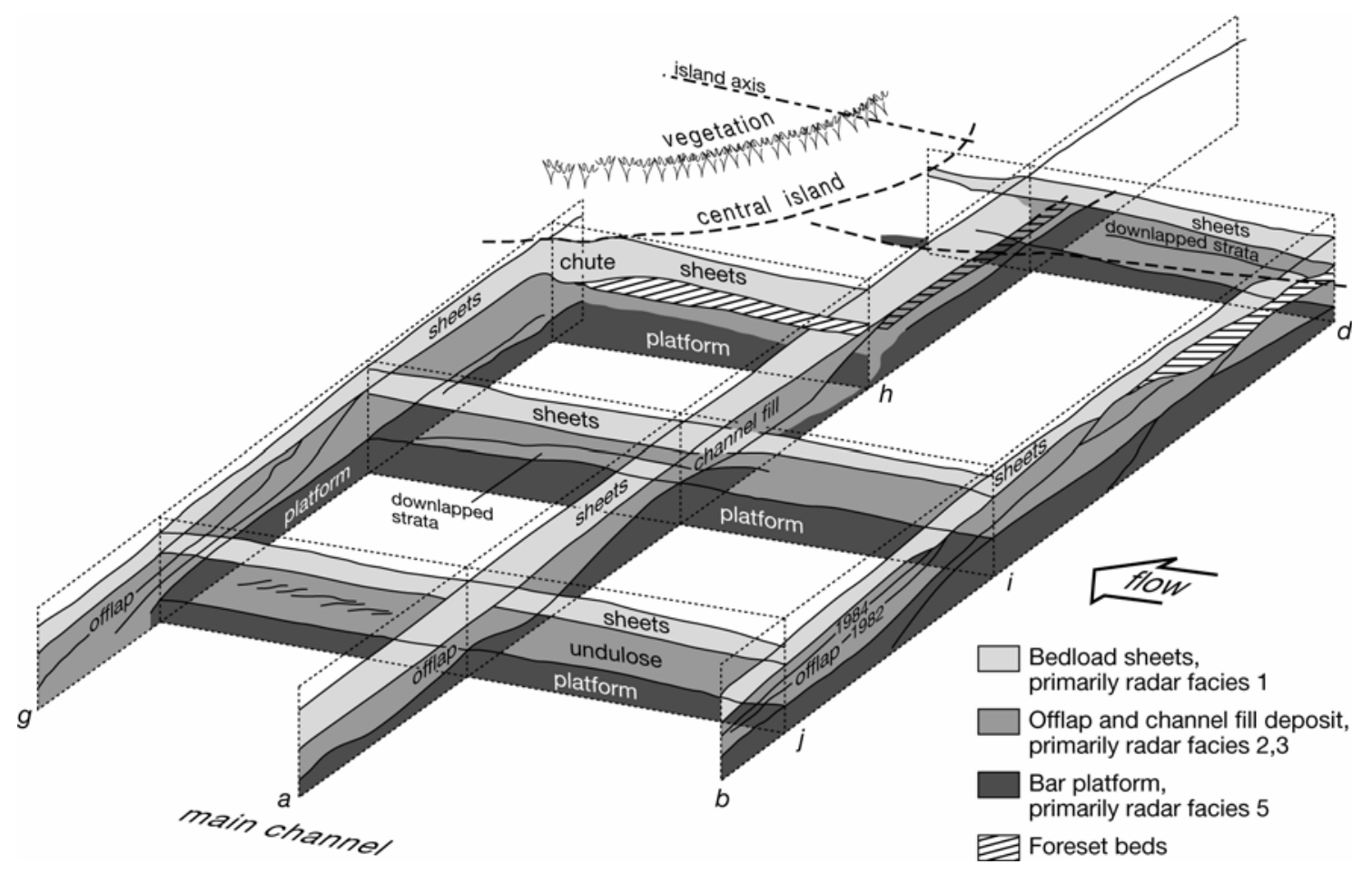


Figure 17. GPR profiles (i) and interpreted profiles (ii) on Queens Bar: (A) Flow-normal profile in the major seasonal anabranch (summer) channel $(100 \mathrm{MHz}, 1.5 \mathrm{x}$ vertical exaggeration); (B) flow-parallel profile in the same anabranch $(100 \mathrm{MHz}, 1.5 \mathrm{x}$ vertical exaggeration). The inset map shows the locations of these two transects on Queens Bar.

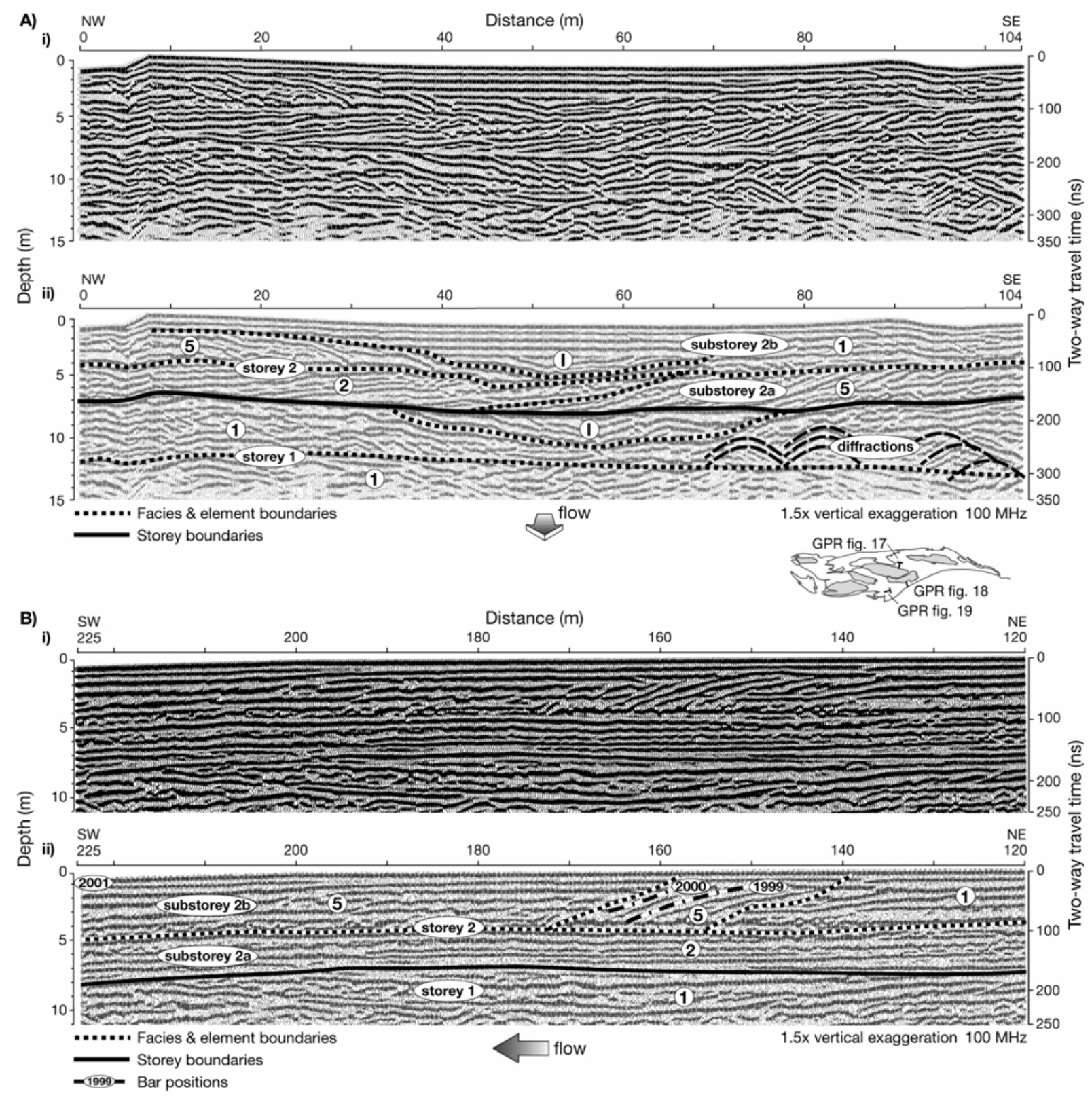


Figure 18. GPR (i) and interpreted (ii) flow-normal profile at the edge of the principal channel (200 MHz, no vertical exaggeration). The inset map on Figure 17 shows the locations of these two transects on Queens Bar.

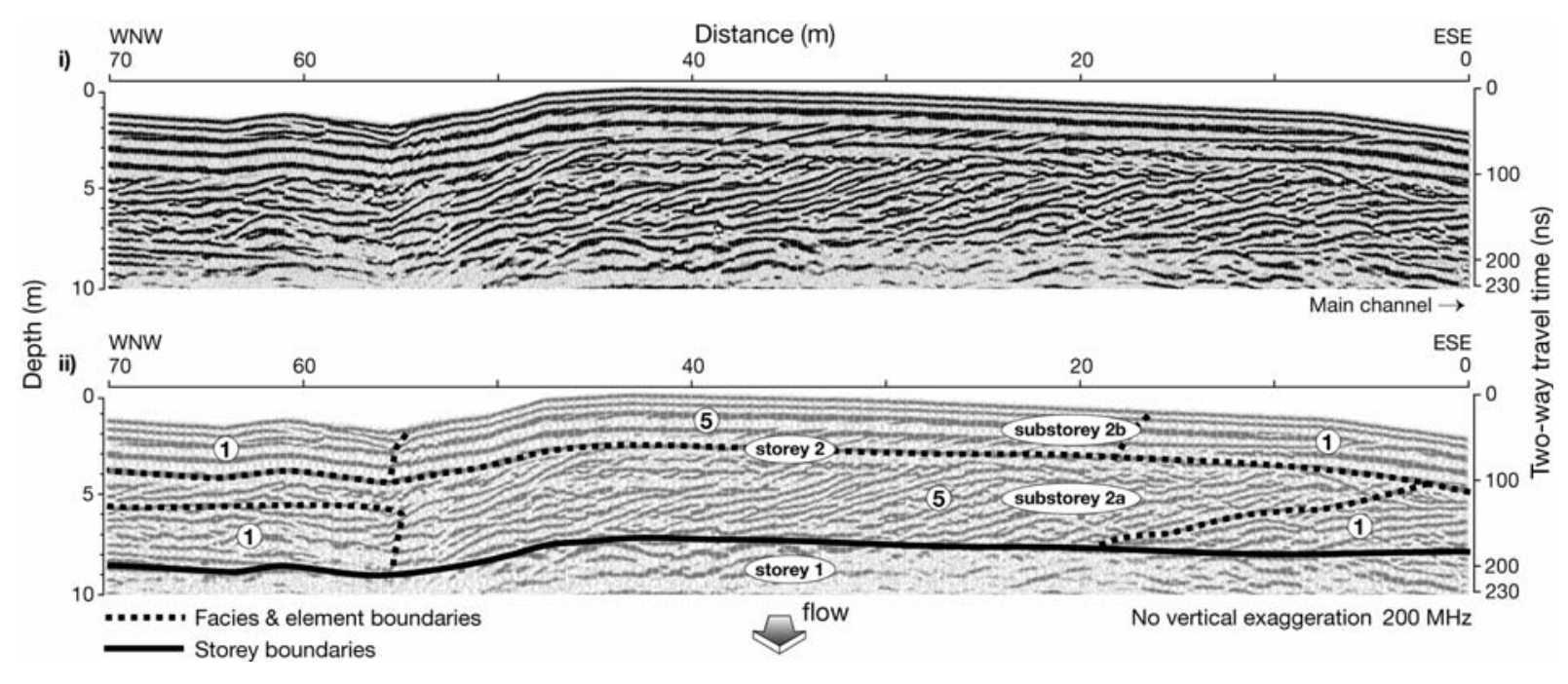


Figure 19. GPR (i) and interpreted (ii) flow-normal and flow parallel profiles on the tail of the recently accreted flank unit bar.(50 MHz, $1.8 \mathrm{x}$ vertical exaggeration). The inset map on Figure 17 shows the locations of these two transects on Queens Bar.

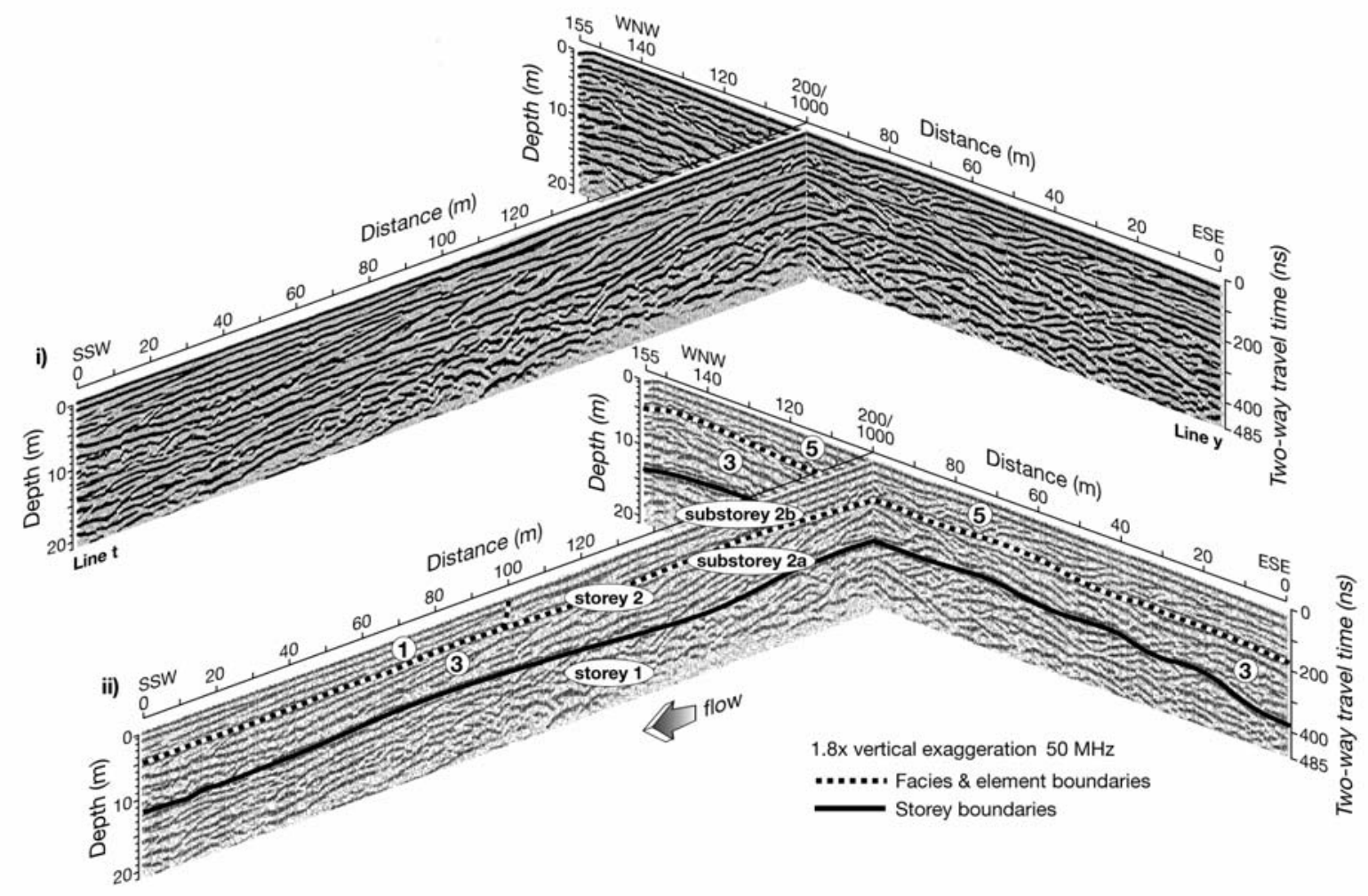

